\title{
Análisis histórico y arqueológico en el contexto del planeamiento urbanístico. El barrio de S. Antón (Granada)
}

\author{
Juan A. García Granados *
}

\section{INTRODUCCIÓN}

Presentamos aquí en su estado, sólo ligeras modificaciones en las ilustraciones, el trabajo realizado para el Plan Especial de Protección y Reforma Interior del Sector 19/San Antón del Avance del Plan Especial del Conjunto Histórico de Granada. Aprobado el Avance del Plan Especial, cuando se redactan estas líneas (mayo de 1996) se encuentra en estado de letargo. Debido al interés de dos grupos promotores en sendas unidades de actuación en la zona, se procedió a redactar un planeamiento específico para uno de los sectores definidos en dicho avance, el correspondiente al barrio de S. Antón. Si tenemos en cuenta que se trata de un sector del Plan Especial del Centro Histórico cabría suponer que ya vendrían dados los análisis correspondientes y que se asumen todas las conclusiones del mismo, limitándose a especificaciones técnicas a nivel de normativa y ordenanzas. La normativa arqueológica, como es natural, se limitaba a recoger lo establecido el referido Avance. No obstante el informe técnico de la Delegación Provincial de la Consejería de Cultura de la Junta de Andalucía puso una serie de objecciones al texto de dicho plan. Resaltamos las principales:

"El análisis de la evolución histórica del sector resulta incompleta, limitándose tan solo a una recopilación de planos y no a un estudio que permita entender la trama urbana, la parcelación y alineaciones, sus posibles transformaciones y evolución (superposición de las distintas épocas), para sustraer los datos que a posteriori pudieran apoyar las Areas de intervención propuestas o las cautelas arqueológicas posibles, e incluso la importancia en la evolución histórica de la edificación existente."

"El catálogo realizado es bastante incompleto, no tanto en la cantidad y calidad de los edificios catalogados, sino en cuanto a los apartados que enunciamos a continuación:

- Criterios seguidos para la catalogación

- Documentación gráfica:

Plantas, secciones, alzados, fotografias

- Análisis de las transformaciones y modificaciones realizadas en estos, a lo largo de su historia.

- Detalles gráficos o fotográficos de los ele mentos de interés"

"Una vez revisado el documento en cuestión se han deducido diversas precariedades en cuanto a la Normativa Arqueológica se refiere, entendiéndose como fundamentales para su normal y buen funcionamiento. Estas serían las siguientes:

- En primer lugar no se establece ninguna zonificación gráfica específica que permita evaluar en cada caso el tipo de intervención que se ha de realizar, así como el porcentaje de excavación necesario.

Junto a este tema no se especifican otras cuestiones como son:

* Arqueólogo Profesional 
- Sobre quien deriva el coste de la intervención arqueológica y quien la asumirá en el caso de ampliación del tiempo previsto para la ejecución de la actividad arqueológica.

- En relación a esto no se establece el tiempo máximo ni mínimo que debe tener la intervención.

- Así mismo existe un vacío en lo que respecta a la necesidad de conservar los restos arqueológicos que fueran documentados, debiendo constar quien asumirá el coste que de todo ello se derive.

Para finalizar centrándonos en los distintos niveles de protección que se establecen, concretamente en el Nivel A3 no ha lugar en caso de aparición de restos arqueológicos, la aplicación del artículo 50 de la Ley de Patrimonio Histórico de Andalucía, puesto que el mismo se refiere a hallazgos casuales, y no a zonas previamente calificadas de riesgo arqueológico."

Al objeto de subsanar dichas carencias el arquitecto redactor, Carlos Quintanilla Moreu, nos encargó un estudio histórico-arqueológico y la revisión del catálogo de edificación. Se publica aquí sólo lo primero. Nos limitamos a exponer el documento final, sin desarrollar los numerosos aspectos metodológicos y la problemática que se deriva tanto del propio análisis del contexto espacial como de su formalización en un instrumento de gestión urbanística. En cuanto lo primero, la finalidad instrumental del trabajo realizado ha hecho que nos centremos en aquellos problemas que tienen una consecuencia directa en la gestión patrimonial, obviando algunos aspectos de investigación histórica puramente académica, como referencias bibliográficas pormenorizadas.

La división rígida en dos apartados, histórico y arqueológico, viene impuesta por la propia normativa del planeamiento. Algunos aspectos previos de descripción del contexto espacial tampoco vienen incluidos aquí por encontrarse en otro lugar del documento de planeamiento. Sólo añadimos algunas puntualizaciones en esta introducción.
Partimos de que debemos explicar el proceso histórico de configuración espacial de la zona. Para ello tenemos en cuenta dos premisas:

a.- No es suficiente establecer una serie de generalidades desde la proyección de principios tipológico-espaciales sino que debemos precisar el modo en que dichos principios se formalizan en la zona estudiada.

b.- Dicho proceso historico implica análisis que corresponden a distintas disciplinas que deben ser contrastados al objeto de definir un estado de los conocimientos y desconocimientos del proceso histórico referido a la zona y una problemática específica localizada en el plano.

En el Avance del Plan Especial del Centro Histórico de Granada el estudio arqueológico constituye un cuerpo separado de otros como el catálogo arquitectónico o el propiamente urbanistico. Dicho Avance establece una zonificación histórico-arqueológica "siguiendo criterios históricos y arqueológicos", es decir, "se ha tenido en cuenta el modelo de desarrollo históricoarqueológico de cada área, que nos es conocido a partir de los hallazgos aislados y especialmente por los resultados de las intervenciones llevadas a cabo y de los edificios monumentales islámicos conservados o citados en las fuentes". En el "catálogo arqueológico" anexo los edificios islámicos conservados son incluidos como "objetos" arqueológicos, con exclusión de cualquier otra estructura posterior. Nuestro trabajo, por el contrario, considera cualquier tipo de documentación que suponga un indicio que nos permita reconocer el proceso histórico-espacial de la zona.

La distinción que efectuamos entre arquitectura tradicional (anterior al siglo $X I X$ ), siglo $X I X$ y reciente, no se refiere de manera estricta a cronologías, aunque en el plano correspondiente se ha intentado apurar el período, sino a grupos tipológicos que producen distinto grado de incidencia en el substrato arqueológico. La primera corresponde por lo general a la casa-patio y construcciones afines: muros de carga en crujías estrechas, la segunda es la casa de pisos burguesa que salvo las tipologías 
de los siglos XVII y XVIII que no corresponden en sentido estricto con la casa-patio, muy poco estudiadas, tiene especial desarrollo en el siglo XIX. Por último las construcciones recientes que corresponden a técnicas constructivas que implican amplios vaciados del subsuelo.

En las tipologías tradicionales puede darse el fenómeno de una reorganización estructural y espacial de construcciones pertenecientes a momentos históricos anteriores englobadas en la construcción conservada '. Existen baños árabes convertidos en viviendas, casas islámicas aprovechadas parcialmente en palacios renacentistas, por no hablar de las casas moriscas y su problemática específica: su posible entendimiento como permanencias islámicas o elementos significativos del proceso de aculturación posterior a la conquista castellana. A veces se ha producido una regularización de huecos en fachada, actuación muy generalizada en el siglo pasado, auténticas rehabilitaciones superficiales que permitían homogeneizar y modernizar el escenario urbano. Las segundas (siglo XIX) corresponden a modos de proceder que raramente van a asumir construcciones anteriores, por incompatibilidades distributivas y estructurales. Por tanto cuando se encuentran en un casco histórico suponen una sustitucion total de las primeras, que sólo permanecen en el subsuelo con toda su complejidad pluriestratigráfica.

Las previsiones arqueológicas derivadas de la presencia de dichas tipologías son fáciles de entender. En las tipologías tradicionales parte de las estructuras conservadas pueden corresponder a un complejo arquitectónico que se encuentra parcialmente enterrado y destruido, por tanto carece de sentido que se impida el estudio arqueológico de las partes visibles de las estructuras y se exiga la documentación de las partes destruidas y sepultadas. Las segundas suponen la existencia de complejos arquitectónicos con distribución no deducible de las estructuras visibles, al tiempo que una mayor complejidad estratigráfica y dificultad de lectura debido a las destrucciones ocasionadas por la yuxtaposición de la tipología mas reciente.
Las últimas casi siempre implican la destrucción de los niveles arqueológicos.

La relación entre tipologías edilicias, fecha de construcción, valoración del estado de conservación y complejidad del substrato arqueológico es directa y graduable. Se une a su ubicación dentro de las distintas áreas generadas en el proceso de expansión de la ciudad histórica. Se generan así dos escalas de referencia, la horizontal de progresiva ampliación espacial desde unos núcleos iniciales de poblamiento, y la vertical de sustitución de las estructuras construidas; parámetros a los que se puede asociar otros tipos de información. Este criterio implica incorporar al documento de diagnóstico arqueológico documentación específica arquitectónica, lo cual presenta problemas metodológicos puesto que se trata de dos ámbitos diferenciados en la redacción del planeamiento, normalmente encomendados a sendos equipos y elaborados de manera simultánea y paralela.

En San Antón la puesta a nuestra disposición del catálogo arquitectónico para su revisión y la que efectuamos de toda la arquitectura del barrio en trabajo de campo, nos ha permitido una gran flexibilidad de trabajo.

Siempre hechamos en falta la concrección a la hora de valorar el estado de conservación de los inmuebles. Hablar de estado de conservación bueno, malo o regular, sin precisar a qué patologías se refieren, nos ha parecido de escasa utilidad, siendo preferible que se indique la patología detectada. En nuestro caso, además, dicha referencia se refiere también a los potenciales niveles arqueológicos. En función de la finalidad propuesta hemos diferenciado tres grandes grupos: a.- De riesgo; b.- Consolidadas; c.- Destruidas.

Por parcelas consolidadas entendemos aquellas que muestran evidencias de obras de mantenimiento, consolidación o rehabilitación recientes; implica que no van a sufrir ninguna alteración en el plazo de vigencia del planeamiento que afecte a potenciales restos arqueológicos. Las destruidas se refieren a las construciones donde

I A manera de paradigma véase la Casa Mañara en Sevilla, actual sede de la Dirección General de Bienes Culturales. 
los niveles arqueológicos han sido afectados de manera grave. El resto queda como parcelas de riesgo. La finalidad de esta información es evaluar las áreas de reserva arqueológica disponibles al objeto de establecer una estrategia de investigación adecuada. Dicha estrategia debería ser formalizada en el contexto del correspondiente proyecto de investigación de arqueología urbana.

Entendemos siempre que dichas previsiones se refiere al momento de redacción y que se van a ir modificando a lo largo del período de vigencia del planeamiento; por tanto debería ser objeto de revisión periódica. Uno de los principales problemas que se plantea en las relaciones entre patrimonio arqueológico y normativa urbanística se refiere a la rigidez de las cautelas preventivas. Frente al uso establecido en los catálogos de protección del patrimonio construido las zonificaciones arqueológicas no se refieren a hechos probados sino a previsiones potenciales y a un estado parcial de los conocimientos. Es por estos que las consideraciones sobre el potencial arqueológico de una zona contenidos en el planeamiento urbanístico no puede ser mantenidas inmutables en su período de vigencia. Las especificaciones se refieren a zonas homogéneas, cronológicas, urbanísticas o topográficas, según las apreciaciones en superficie. La posterior intervención arqueológica puede definir áreas homogéneas correspondientes a los depósitos del subsuelo diferentes de aquellas. Por ello una actualización periódica de las previsiones arqueológicas establecidas a nivel de normativa urbanística es indispensable, sin embargo este hecho nunca se produce.

Por tratarse de un documento no dirigido a especialistas en arqueología hemos considerado necesario explicitar la argumentación que articula una diagnosis arqueológica, algo innecesario en un contexto de pura investigación. Al respecto debemos resaltar la importante carencia de regulación normativa sobre los contenidos de dicha diagnosis a efectos de regla- mentación urbanística en la legislación de nuestra comunidad autónoma.

Respecto la posible normativa y ordenanzas que articulen la protección e intervención arqueológica, sólo indicamos los principales artículos de la legislacion mas reciente al objeto de facilitar la redacción definitiva por el arquitecto director del planeamiento.

\section{PROCESO HISTÓRICO}

\section{Evidencias históricas.}

\section{A. La Antigüedad.}

En lo referente a la Antigüedad, el único testimonio de la ocupación de la zona es el hallazgo de un enterramiento íbero-romano hacia el final de la calle S. Antón, posiblemente en base a su relación con los ríos Darro y Genil. Situado a una profundidad en torno a los cuatro metros, y a una distancia que hace poco probable su relación con la zona investigada aun en el caso de tratarse de una necrópolis de cierta amplitud.

\section{B. La estructura medieval}

El carácter periurbano de la zona en el siglo XI viene establecido por la existencia de una almunia real en el arenal del río Darro "la Rambla", según las Memorias de Abd Allah.

El pago del Jaragüi constituía la zona entre los ríos Darro y Genil al Suroeste del casco urbano medieval. Se subdividía en Jaragüi Alto, con una extensión de 794 marjales, y Jaragüi Bajo con 976 marjales $^{2}$. La naturaleza de la zona en época nazarí viene dada a través de varios datos.

Torres Balbás recoge la cita en el siglo XV de los "molinos de Jarambi" "cerca de la puerta de Bibarrambla"(sic) quebrados por el rey Católico en 1488 en una de sus entradas por la Vega de Granada ${ }^{3}$. Los libros de habices inciden en la naturaleza de zona agrícola 4 .

\footnotetext{
2 Según un apeo de 1644 recogido por Garzón Pareja, Historia de Granada, I, p.377 Granada I 980. El primero con 3 I propietarios, el segundo con 26 propietarios.

3 Torres Balbás, L. Ciudades hispanomusulmanas. Madrid. 197 | p. I59. Cita de Pulgar. Crónica de los Reyes Católicos. II p. I25)

4 Hernandez Benito, P. La Vega de Granada a fines de la Edad Media según las rentas de los habices. Granada 1990.
} 
(85) "Una haça en el Jaragui de dyes marjales, tyenela Malpica, vezino a Bib Almasda por XXXIII ps. cada anno..."

(86) "Otra haça en el dicho pago de otros dyes marjales, tyenela Francisco el Juljel yerno de Aben Reduan por $X X X V$ ps. cada anno..."

(102) "Otra haça en el Jaragui, tyenela Aben Çuleiman vezino del Albaiysin a XX ps. cada anno..."

(474) "Otra haça en el Jaragui de cuatro marjales alinde del Partal, Tyenela Juan Mahamed Palomino vecino a Rabad Albayda por XVII ps. y medio cada anno..."

(506) "Medio molino en el Jaragui que solia cobrar los annos pasados Juan Ynfante y quedo este año desbaratado por las creçientes del Ynvierno pasado, suele rentar de CCC mrs. hasta quinientos mrs. cada mes, un anno con otro".

(907) "Otra haça media en el Jaragui en compania de otra media del algima, es de VII marjales alinde del Milandy, tyenela toda Juan de Santa Crus el Bayady en XII reales cada anno..."

(977) "otra haça en el Jaragui tyenela Bernardo de Malpica vezino a Bib Almasda en $X X V$ reales cada anno, desde este anno de 503 hasta quatro annos."

Según el apeo de 1506 de las rentas de propios para castillo fronteros el tamaño de las parcelas oscilan en términos generales entre 5 y 10 marjales 5.

\section{C. siglos XVI-XVII.}

La zona mas inmediata al casco urbano y la muralla urbana era la "huerta de Jedida" (Gidida?) perteneciente a una hermana de Boabdil y cedida al licenciado Andrés Calderón, corregidor de Granada, por los Reyes Católicos en abril de 1492. En ella se desarrollará el barrio de la Magdalena. Su borde inferior venía dado por una acequia, límite que se mantiene en el siglo XVII y justifica el trazado irregular de las últimas manzanas del barrio.

Aunque la proximidad al arrabal de Bibarrambla pudiera hacer pensar en un nivel alto de edificaciones, en todo caso las mismas estarían subordinadas a la trama de caminos rurales, sin que exista ningún dato que nos permita pensar en un barrio incipiente. Algunas construcciones no son en sentido estricto específicamente rurales, como las atarazanas incorporadas al Convento de S. Antón hacia 1565.

La imagen de la zona hacia finales del siglo XVI tal como nos viene dada en la Plataforma de Vico indica que se trata de una espacio donde los componentes rurales son aún muy fuertes. Todo el ámbito hacia el Sureste extramuros de la ciudad constituyó la parroquia de la Magdalena. Sólo cuando ya está avanzado el siglo XVII se consolida la urbanización de las huertas del Convento de Santo Domingo se cede parte de su territorio a la nueva parroquia de la Virgen de las Angustias.

Sólo dos edificios importantes se elevan en la zona: El Convento de S. Antón que configura una plaza delante de donde parten las calles Puentezuelas, Recogidas y de S. Antón, dicho edificio constituye la emergencia arquitectónica que articula todo el barrio. Asentados en el siglo XVI tras el traslado desde una primera ubicación junto a la ribera del Genil existe una primera iglesia, dibujada ya en 1567 por Wingaerde, que será sustituida por otra construida entre los siglos XVII y XVIII ${ }^{6}$. El otro edificio es el Beaterio de St. María Egipciaca, fundado en 1595 y concluido en 1643; define el primer tramo de la calle Recogidas.

\section{Los elementos espacio-funcionales}

Dentro del análisis histórico consideramos esencial el estudio de aquellos indicios presentes en la planimetría que evidencian determinados modos de organización espacial y los

5 Luna Diaz, J.A. La parroquia de Santa María Magdalena de Granada un barrio en expansión hacia la Vega en el siglo XVI. Chronica Nova, p.219.

6 La existencia de una iglesia anterior a la actual es dato sobre el que no se ha publicado ninguna documentación, pero el dibujo de Wingaerde no deja lugar a dudas. Para todo lo referente a la construcción de la iglesia: Gómez-Moreno Galera, J.M. La arquitectura religiosa granadina en la crisis del Renacimiento ( I 560- | 650), pp.203-208. 
distintos procesos de transformación subsiguientes. Centramos la atención en tres hechos: El parcelario inicial y sus transformaciones, la configuración de la trama viaria, y el proceso de urbanización deducible de las evidencias anteriores y de las tipologías funcionales y edilicias presentes en la zona.

\section{A.- El parcelario.}

El plano de Dalmau ofrece una información fundamental sobre la periferia urbana que hasta ahora no ha sido valorada: el parcelario de las huertas en torno al casco urbano corresponde al estado real del mismo a fines del siglo XVIII. Podemos comprobarlo por medio de la comparación con la fotografía aérea de la zona a mediados del siglo $X X$, que incluso nos permite verificar errores de alineación en el plano, como puede verse en la información gráfica que adjuntamos.

Aun con los inevitables cambios producidos desde la conquista castellana, la imagen general del parcelario nos indica una alineación que viene determinada por la distribución de la red de acequias, que constituye referencia estable y junto con el tamaño de las parcelas agrícolas parece que facilitó un determinado modelo de trama urbana, pues sería posible hacer corresponder con cierta facilidad el ancho de la manzana urbana con la parcela agrícola de forma que las lindes correspondieran con los ejes de las calles.

Las posibles construcciones asociadas a dichas parcelas, dispersas y con escasa densidad dada la proximidad al núcleo urbano y la residencia de los propietarios -o arrendadores- en la ciudad, constituye otro elemento de referencia para definir dicho parcelario rural. Su ubicación se produciria en el borde de la parcela y en sentido paralelo a la misma, mientras que la construcción urbana penetra en la parcela perpendicular a su borde o linde.

\section{B.- La trama urbana}

El sistema hidráulico y el parcelario condicionan la organización posterior. El sistema de caminos articula los ejes principales de una trama urbana incipiente que no es producto de un trazado sistemático. Si la calle Recogidas surge como elemento nuevo de carácter urbano asociado a la trama del barrio de la Magdalena, la calle S. Antón es preexistencia de caracter rural: es el camino que conduce desde el casco urbano a los molinos de la ribera del Genil, apoyados en la Acequia Gorda, que permanecen hasta el siglo $X X$, transformados en instalaciones industriales. A su vez, otros dos ejes viarios aparecen condicionados por la preexistencia del trazado de acequias.

La calle Frailes, con su trazado sinuoso, constituye anomalía en la definición de la trama urbana, no justificada por criterios topográficos. La clave nos la da la Plataforma de Vico, donde la "acequia madre" que sale de la ciudad se bifurca en varios ramales hacia el barrio de la Magdalena y el barrio de S. Antón, este último envolviendo el convento por el Oeste. Una nueva bifurcación define dos ejes correspondientes a las actuales calles de los Frailes y S. José Baja. La primera sigue hacia la Vega definiendo el borde inferior de los nuevos barrios. La calle S. José Baja marca, por tanto, un elemento de referencia que articula el parcelario en dos direcciones, hacia la calle Recogidas y hacia la calle S. Antón.

El carácter de zona semirural: Trama que define un viario urbano hacia el exterior y que mantiene en el interior de las manzanas usos agrícolas, caracteriza el siglo XVII, tal como es visible en la Plataforma de Vico y lo describe Jorquera "La calle de S. Antón pondremos como la principal de sus grandes barrios y nueva población, por ser ella la que da entrada a largas calles que arruinando huertas se aumentan nuevos habitantes. Tiene su principio en la plazuela de S. Antón, por el gran convento, y remata cerca de los molinos dando vista a el Genil dividiendo esta calle esta grande población [parroquia de la Magdalena] y la de las Angustias que por las tomas de agua se avecinda a el Darro. Sus calles son muchas y de bizarros edificios, con diversos jardines, algunos de ellos casi se pierden de vista como son los de San Miguel, la de S. Joseph y otros muchos que se incorporan con las guertas" (Jorquera l, p.30). 
En resumen, la zona indicada no tiene relaciones reconocibles con la estructura urbana medieval como ámbito funcional periurbano. La calle $\mathrm{S}$. Antón puede entenderse como una via preexistente a la calle definida por la trama urbanizada, por lo cual, las posibles instalaciones dependientes de la proximidad al rio Darro deben atribuirse a la faja externa a la zona objeto de planeamiento.

\section{C.- El proceso de urbanización}

Las opciones del crecimiento urbano al exterior del recinto amurallado son de dos tipos:

A.- Conversión de espacios agrícolas en urbanos mediante parcelación sistemática. Operaciones "inmobiliarias" de parcelación y venta. Sucede con los barrios de Duquesa y de las Angustias, el primero adquirido por un genovés, el segundo producto de la venta de toda la zona comprendida entre la huerta de Almanjarra Alta y el rio Darro por el Convento de Santo Domingo.

B.- La otra opción es una urbanización "espontánea" debido al cambio funcional del parcelario mas inmediato al casco urbano. Se intensifica la construcción en los bordes de las parcelas agrícolas siendo probable que se produzca una correspondencia sistemática entre ambas. Se define la calle S. Antón como eje urbano. Mediante la construcción de viviendas permanentes a lo largo de los caminos preexistentes con tipologías arquitectónicas propiamente urbanas y, a mas largo plazo, una reorganización de las viviendas rurales, modificándose el uso rural mediante la reconversión total o parcial de la parcela desde huerta a jardín. esta segunda opción, con su desarrollo en los bordes de las parcelas agrícolas impermeabilizádolas, dificulta, en caso de consolidarse, una trama propiamente urbana, dando lugar a islotes propiamente rurales. Es un fenómeno que caracteriza la expansión de la ciudad hacia el Oeste y que sólo se elimina en la segunda mitad del siglo $X X$.

Puede afirmarse que el barrio de S. Antón nunca llega a integrarse con carácter pleno en el casco urbano granadino, manteniendo un carácter de espacio de transición hasta el siglo
XX. La conexión tardía con la otra ribera del rio Darro a través de los puentes de Castañeda y de la Virgen y la falta de continuidad entre el viario de los barrios de la Magdalena / Gracia e incluso con las manzanas de la ribera del rio Darro a lo largo de la calle S. Antón vendría a mostrar la falta de una actuación urbanística "programada" de diseño general del barrio.

El proceso posterior al plano de Dalmau en su consolidación definitiva muestra un episodio de interés en la modificación del viario y regulación de la calle Nueva de S. Antón en su tramo final de encuentro con la calle S. Antón, de forma que la conexión con la calle Puente de Castañeda se modifica mediante la supresión de quiebros.

Las principales actuaciones urbanísticas en el siglo $X X$ se refieren a dos operaciones que afectan a vias perimetrales: el ensanche de la calle Recogidas, en la segunda mitad de la década de los 50, alineándola con la fachada de la iglesia de S. Antón. Redujo la profundidad de las manzanas del siglo XVIII ( $n^{\circ}$ s I y 2 del presente plan). Operación mas radical fue el proyecto de ronda de circulación interior propuesto por el Plan General de Ordenación Urbana de 1973, donde la prolongación de la Gran Via atravesaba el barrio de S. Antón para enlazar con la calle Pedro Antonio de Alarcón. Dicha propuesta es la que ha dado como consecuencia el ensanche de la calle Nueva de S. Antón en su tramo central.

\section{D.- Las tipologías edilicias}

El proceso indicado nos permite deducir la existencia de tipologías específicas a cada uno de los distintos momentos históricos y funcionales de la zona.

I.- Tipologías medievales. Pertenecen a las categorías rurales y periurbanas, es decir, cortijos/almunias, molinos en zonas específicas, aparte de otras como las atarazanas, asociadas a la producción de cáñamo, o potenciales como rábitas. Ubicación dispersa, en función del parcelario agrícola, sin que sea probable que existan estructuras construidas correspondientes a cada una de dichas parcelas. 
2.- Siglo XVI. La organización en función del borde favorecería una tipología encrujías paralelas al camino/calle, bien como casa-patio en los casos de mayor categoría social o abiertas hacia los huertos interiores. La tipología viene dada en parte por agrupaciones en viarios próximos como fueron las "casillas de Prats" en lo que hoy es la Plaza de Menorca. Construcciones de una sola crujía paralela al camino que pueden tener en su parte posterior otras edificaciones menores.

3.- Siglos XVII-XVIII. El proceso posterior supondría la ocupación sistemática de las parcelas con una ocupación en profundidad. En este caso parece claro que las posibilidades de una parcelación sistemática están condicionadas por el grado de consolidación de las propiedades construidas, lo que puede dar lugar a dos procesos distintos:

A.- reforma y acondicionamiento de las viviendas preexistentes; bien modificando características rurales mas o menos acentuadas, bien expandiéndola hacia el interior de la parcela mediante el añadido de nuevos cuerpos o efectuando una sustitución general de las estructuras.

B.-Puede suponer agrupación de varias parcelas agrícolas al objeto de establecer una reorganización mas homogénea de las manzanas de viviendas. Pueden introducirse ya desde un principio las viviendas plurifamiliares de tres plantas.

\section{ANALISIS DEL CONTEXTO ARQUEOLÓGICO}

\section{Criterios de valoración y de análisis}

Recogemos aquí lo expuesto por Ignacio Rodríguez Temiño y Miguel Puya sobre los criterios de evaluación del contexto arqueológico urbano ${ }^{7}$ :

"identificando los niveles arqueológicamente fértiles de una ciudad con su gran archivo de documentos no escritos, la diagnosis previa deberá enfocarse a la delimitación y evaluación del potencial informativo existente en el momento de incoar el procedimiento de catalogación".

"La base inicial de esta documentación es la carta arqueológica. Su función principal consiste en inventariar y registrar sobre el plano todo el conocimiento existente sobre el pasado histórico de la ciudad acudiendo para ello a todas las fuentes de información disponibles -arqueológicas o no- entendiendo que no debe concebirse como la mera suma de datos, sino como la recopilación de las evidencias conocidas de la evolución cronológica de un conjunto interrelacionado de sistemas estructurados; lo que permite la formulación de hipótesis interpretativas sobre cada uno de ellos. Desde este punto de vista adquieren igual importancia los datos conocidos y las lagunas de información sobre cada período histórico".

"La carta arqueológica debe ir acompañada de otro documento donde se evalúe aquello que ha venido a denominarse la "erosión de la historia". Se trata de la cuantificación de la pérdida de información -mediante la remoción o alteración de los sedimentos arqueológicos- producida durante el propio devenir histórico de la ciudad... dos nuevos factores han marcado una profunda diferencia con lo anterior: los procesos de reurbanización, que han afectado notablemente las alineaciones históricas del parcelario medieval heredado, y el rápido proceso de sustituciones, con nuevos tipos de cimentaciones mas profundas y, sobre todo, con la ejecución de garages en planta de sótano."

"Esta información contrastada con la potencia de los niveles arqueológicos en las distintas áreas de la ciudad, comprobadas a través de las excavaciones, nos dará el porcentaje aproximado de documentación perdida de forma global y por áreas, e incluso, por etapas históricas".

"La unión de ambos documentos ofrecerá el panorama real de lo que se ha perdido y de lo que resta, detectándose de igual modo aquellas zonas en situación crítica donde sólo queden contadísimos lugares viŕgenes con información suficiente para evitar el desconocimiento irremediable de su evolución histórica. La traducción cartográfica de estos resultados son las conocidas como cartas de riesgo".

7 "Zonas arqueológicas en ciudades actuales", en Casa palacio de Miguel de Mañara: Restauración. Sevilla 1993. 
"las cartas de riesgo son los documentos que analizan la información existente a fin de evaluar la probable capacidad de los depósitos arqueológicos de cada etapa cronológica, así como las reservas bajo suelo público, poniendo de relieve las posibilidades de documentación de cada área. El panorama resultante de la conjugación de las distintas cartas de riesgo se formalizará en un conjunto de áreas de características diversas, cuyas particularidades serán determinantes en la evaluación y toma de decisiones sobre el patrimonio arqueológico".

El resultado de todo ello será la delimitación global del bien objeto de catalogación específica (que en estos casos carecerá de entorno), así como el establecimiento de un conjunto articulado de zonas dentro del ámbito de la Zona arqueológica inscrita, atendiendo a los diversos criterios elegidos para la elaboración de las cartas de riesgo y otros parámetros de evaluación: la densidad de restos arqueológicos, la disposición de solares o casas no catalogadas en mal estado, la zonificación de áreas en función del conocimiento que tenemos de su evolución cronológica y otros similares".

\section{Características del proceso histórico}

El proceso histórico conocido, tal como es analizado en el apartado correspondiente, deriva en una serie de conclusiones e hipótesis derivadas de distintas fuentes documentales:

Documentación escrita: Ausencia de datos que indiquen un posible núcleo habitado periurbano en época medieval. Presencia de almunia en el siglo Xl. La zona corresponde a usos agrícolas dominantes con un área de molinos en el borde del rio Genil-Acequia Gorda.

Documentación gráfica y planimétrica. Imágenes del siglo XVI y Planimetría de los siglos XVIII-XX. Nos informan de varios hechos:

A.- Existencia de permanencias de tipo rural:

- Camino a los molinos (Calle S. Antón)

- Acequias que van a condicionar el proceso urbanístico posterior.
B.- Una indefinición a nivel de trama urbana que da como resultado las actuales manzanas 6 y 8 que deben entenderse como derivadas de una consolidación periférica de las parcelas agrícolas originales que dificultó el diseño de una trama homogénea, adecuada a las tipologías edilicias vigentes en los siglos $X V I I-X V I I I$, que es el momento en que se consolida la zona.

En conjunto nos parecen evidencias suficientes para establecer como hipótesis inicial que se trata de un área agrícola que adquiere naturaleza de zona periurbana desde el siglo Xl, donde los usos agrícolas y la infraestructura que la acompaña permanece a lo largo de todo el proceso de transformación en espacio urbano, proceso tardío y nunca plenamente concluido.

Existen también lagunas en nuestro conocimiento, referidas sobre todo a los momentos históricos mas tempranos. El único dato disponible sobre los usos de la zona en la Antigüedad es una sepultura en la zona próxima al rio Genil que nos informa sobre las modificaciones de los niveles históricos producidos como consecuencia de las crecidas periódicas del rio Darro, que tiene como consecuencia una importante acumulación de sedimentos y define un horizonte histórico a un nivel entre tres y cuatro metros por debajo de la rasante del terreno actual.

Existen, por tanto, dos series discontinuas

I.- Proceso desde la Antigüedad hasta la configuración del espacio agrario medieval

2.- Proceso desde la consolidación del espacio agrario medieval hasta su configuración como zona urbana. En este segundo la temprana construcción de la acequia Gorda -siglo XI al parecer- junto con la delimitación del casco urbano mediante las murallas permite establecer una subdivisión teórica:

a.- Fase Altomedieval previa al asentamiento urbano en el llano

b.- Fase Bajo medieval-moderna. Desde el siglo Xl. Las relaciones espacio-funcionales derivan de su naturaleza periurbana. 


\section{Tipos de restos arqueológicos}

Los posibles restos existentes pueden referirse a dos niveles de conocimiento:

\section{A.- E structuras/Nivel arquitectónico}

I.- Estructura. Entendiendo por tales también las negativas (fosas, canales, etc) (Características morfológicas y constructivas)

2.- Ambiente o ámbito. (Unidad espacial).

3.- Correspondencia entre unidades espaciales adyacentes. Tipologías funcionales.

4.- Complejo arquitectónico. Tipologías edilicias. Usos espaciales

5.- Depósitos asociados a las estructuras

\section{B.- Espacios/Nivel urbano}

6.- Parcelario rural / urbano. Unidad urbanística,

7.- Trama urbana. (Manzana)

8.- Sistemas generales de infraestructura urbana

La actuación arqueológica limitada a la parcela supone un reconocimiento de las posibles estructuras comprendidas en la misma. Si tenemos en cuenta el proceso espacial descrito, la posible correspondencia entre estructura y parcela adquiere varios significados:

La existencia de estructuras no correspondientes al parcelario del siglo XVIII pondría en evidencia una organización espacial anterior al sistema urbano generado entre los siglos $\mathrm{XVI}$ y XVIII. No obstante es posible que si el mismo ha estado condicionado por el parcelario agrícola en un proceso lento se produzcan situaciones mas complejas:

I.- Presencia de construcciones asociadas a las funciones agrícolas de la parcela.

2.- Construcciones asociadas a la definición de un viario urbano incipiente. (Desarrollo perimetral).

3.- Ocupación en "manzana densa". Construcciones desarrolladas en profundidad ocupando todo el fondo de parcela.
En el caso mas complejo posible todas estas fases podrían encontrarse en el mismo espacio. Las dos primeras pueden corresponder a momentos consecutivos o darse sólo uno de los casos.

Un segundo elemento articulador espacial a escala mas amplia es el que deriva del sistema de regadío existente en la zona. Su ubicación es el mas claro indicador de la alineación del parcelario agrícola.

Los elementos a escala urbana son mas difíciles de identificar por medio de intervenciones puntuales mediante sondeos en las parcelas. Las posibles divisiones del parcelario son, por lo general, indicios muy débiles que difícilmente serán identificables en sondeos arqueológicos donde, por otro lado, cabe la posibilidad de que dichos límites, en parte o en su totalidad, correspondan a los bordes de la zona investigada con metodología arqueológica. En principio, los perfiles estratigráficos obtenidos en el vaciado de tierras del solar ofrecen una lectura a escala mas adecuada a la solución del problema planteado que el sondeo puntual.

\section{Diagnóstico de la zona}

Los criterios de protección de un contexto arqueológico vienen determinados por el estado y complejidad de los niveles arqueológicos. En su valoración influyen varios parámetros

\section{I.- Potencia estratigráfica}

2.- Grado de alteración de los niveles arqueológicos

Tipo y ubicación de las infraestructuras urbanas

Distribución de las construcciones de nueva planta que implican destruccion de niveles arqueológicos.

3.- Naturaleza de los restos arqueológicos y complejidad de la pluriestratificación.

4.- Tendencias de transformación.

Estado de conservación de las viviendas en espacios que sólo afecta de forma parcial el sustrato arqueológico. 
El grado de conocimiento arqueológico de la zona es nulo en el sentido de que ningún sondeo ha sido realizado en el área objeto del planeamiento. Los datos que adjuntamos se refieren al grado de alteración derivado de las intervenciones constructivas en la segunda mitad del siglo $X X$, que han supuesto una importante remoción de tierras. Resumimos en cuadro los datos por manzana y los desglosamos en apéndice por parcela. Entendemos como espacio consolidado tanto el ocupado por las nuevas edificaciones como por los edificios rehabilitados.

Grado de conservación del contexto arqueológico $\left(\mathrm{m}^{2}\right)$

\begin{tabular}{|c|c|c|c|c|c|}
\hline Mnz & Superficie & $\mathrm{N}^{\circ}$ Parc & Consolidada & Conservada & $\%$ \\
\hline 1 & 3.818 & 19 & 3.445 & 373 & 9,82 \\
\hline 2 & $* 6.336$ & 6 & 2.230 & 88 & 1,38 \\
\hline 3 & 3.230 & 18 & 1.069 & 2.161 & 66,9 \\
\hline 4 & 3.943 & 23 & 1.293 & 2.650 & 67,2 \\
\hline 5 & 1.607 & 10 & 750 & 857 & 53,32 \\
\hline 6 & 3.745 & 16 & 1.672 & 2.073 & 55,35 \\
\hline 7 & 1.553 & 10 & 746 & 807 & 51,96 \\
\hline 8 & +10.198 & 24 & 2.894 & 7.304 & 71,62 \\
\hline
\end{tabular}

* $3.930 \mathrm{~m}^{2}$ corresponden al Convento de S. Antón.

+ Falta una parcela.

\section{Criterios de normativa}

La carencia de datos positivos sobre la existencia de restos arqueológicos en el espacio analizado no proviene de la comprobada ausencia de los mismos sino de la carencia de intervenciones. Por esto, los criterios de prevención consideramos que deben atender a los parámetros de conocimiento histórico de la zona al objeto de establecer unas precauciones.

Es claro que la zona nunca tuvo una población de naturaleza urbana, ni siquiera como arrabal, durante época medieval. Los condicionantes del sistema hidráulico en el momento del diseño de la trama viaria indica que dichas funciones rurales están presentes en la zona alta mas inmediata al casco urbano medieval, al tiempo que la zona mas alejada ha mantenido hasta el siglo $X X$ usos agrícolas englobados.

En base a dicho contexto, es posible prever una distribución y densidad de los posibles restos arqueológicos que sirva de referencia para establecer qué criterios de intervención parecen mas aconsejables en la zona.

Estamos de acuerdo con Rodriguez Temiño y Miguel Puya cuando indican que debe dotarse al proyecto de excavación "de auténtico carácter definidor de la actuación futura" el proyecto de excavación, "para lo cual habrá que eliminar en la medida de lo posible las incertidumbres sobre la naturaleza y estado de los restos arqueológicos del área donde se actúa, acudiendo al análisis de las excavaciones circundantes u otras noticias de hallazgos que arrojen luz sobre el tema y, especialmente, a técnicas de prospección directa, bien con sondeos puntuales con recuperación de testigos, bien con los métodos que nos proponen la geofisica o con calicatas a mano y/o a máquina realizadas al efecto" 8 . Por esto consideramos apropiado proponer control de movimiento de tierras y sondeos, mecánicos y/o manuales, ya que según dichos autores "Estas técnicas serán especialmente aptas en las áreas donde existan dudas sobre la presencia de restos arqueológicos o de la continuidad de los mismos."

El movimiento de tierras no sirve para documentar partes de estructuras sino su presencia / ausencia, superficie ocupada y orientación de dichas estructuras. Estos datos permiten reconocer un modo de ocupación espacial cuando existen usos nítidamente diferenciados como sucede en la zona que nos ocupa (edificaciones en zona agrícola). Parece convenir con los dispuesto en la normativa del Avance del Plan Especial del Centro histórico en lo referido al grado II: Documentar los paquetes estratigráficos que desaparecerán durante el proceso natural de renovación y sustitución del paquete inmobiliario de la ciudad y sus sistemas generales de infraestructuras.

\footnotetext{
8 "Zonas arqueológicas en ciudades actuales", en Casa palacio de Miguel de Mañara: Restauración. Sevilla 1993.
} 


\section{Determinación de superficie útil excavable por parcela.}

La presencia de estructuras positivas y negativas y depósitos asociados identificados en el transcurso del movimiento de tierras implica su documentación, que puede ser hasta la excavación sistemática si la naturaleza de los restos localizados lo requiriera. La normativa del Avance del Plan Especial del Conjunto Histórico establece unos porcentajes de superficie a intervenir con metodología arqueológica. La justificación de dichos porcentajes es fijar "los metros cuadrados mínimos de excavación que se consideran suficientes para asegurar la correcta documentación de los restos soterrados". Dicha valoración parece claro que no puede establecerse mediante una correlación genérica en función de la superficie de la parcela, sino de las previsiones establecidas por el potencial arqueológico de la zona, donde se valoran las condiciones de las estructuras conservadas y parcelario disponible. A manera de ejemplo vamos a analizar cual es la relación que existe entre la superficie total del solar y la superficie disponible para la intervención arqueológica en condiciones "standard"

En el grafico de la figura 12 se plantean parcelas de distinto tamaño adaptadas a las dimensiones y formas mas frecuentes en el casco urbano granadino y de manera especial en la zona aquí estudiada. A manera de referencia digamos que la parcela mayor, en torno a los 300 metros cuadrados equivale al tipo de casa palacio en torno a patio porticado, que puede disponer además de jardin y construcciones menores anejas. En el caso tipo: parcela entre edificaciones laterales de cronología similar, de cimentación poco sólida, reservamos un espacio perimetral de un metro y otro inmediato a la calle de cuatro metros de ancho para movimiento de tierras. Los porcentajes se superficie máxima excavable en dichas condiciones vienen dados en el cuadro siguiente.

\begin{tabular}{|c|c|c|}
\hline Sup.Total & Sup.Excav. & $\%$ \\
\hline 300 & 195 & 65 \\
\hline 200 & 120 & 60 \\
\hline 150 & 82,5 & 55 \\
\hline 108 & 49 & 45.37 \\
\hline
\end{tabular}

De dichos datos se deduce claramente que los porcentajes establecidos por el Avance del Plan Especial del Conjunto Histórico en sus dos grados máximos : 75-100\% y hasta 75\%, tienen escasa relevancia en la práctica pues sólo efectan a grandes superficies en contextos abiertos.

En base a dicho análisis hemos ajustado la prevision de superficie a intervenir por parcela, en el caso de que la naturaleza de los restos observados en el transcurso del movimiento de tierras así lo requiriera.

Aparte debemos tener en cuenta lo dispuesto por el Reglamento de protección y fomento del Patrimonio Histórico de Andalucía (Decreto 19/1995 de 7 de febrero) establece las siguientes precauciones en zonas de servidumbre arqueológica:

\section{Art. 73}

a.- Orientación de las calificaciones de suelo hacia las áreas de menor riesgo.

b.- Establecimiento de obligaciones específicas para los promotores de actaucione en relación con la realización de catas y estudios previos.

c.- Incorporación de informes arqueológicos a la documentación exigida para las actuaciones

d.- Ordenación temporal de las actuaciones que permita acomodar los programas de investigación arqueológica.

e.- Establecimiento de procedimientos que garanticen el cumplimiento de lo previsto en el art. 49.3 de la Ley I/I99/ para la realización de obras.

f.- Consideración de las obligaciones derivadas de la Ley I/l991 y el presente Reglamento como carga urbanística y establecimiento de las determinaciones necesarias para su reparto con arreglo a lo previsto en el Texto Refundido de la Ley sobre Régimen del suelo y ordenación urbana y legislación complementaria. 


\section{Art. 75}

2. Corresponde a los promotores de las obras o actuaciones remitir a la Delegación Provincial la notificación .... I 5 dias antes, como mínimo de la iniciación de las obras, contándose dicho plazo a partir de la recepción de la mencionada notificación.

3. Recibida la notificación la Consejería de Cultura podrá ordenar la realización de catas o prospecciones arqueológicas en el plazo de 15 dias a que se refiere el apartado anterior, fijando los plazos y condiciones que resulte necesario, 10 que deberá ser ejecutado por el promotor de las obras, según establece el artículo 48.1 de este Reglamento.

\section{Art. 48.}

1. Con caracter previo a la autorización de actuación en zonas arqueológicas y zonas de servidumbre arqueológica, así como en conjuntos históricos en los que el planeamiento urbanístico o las instrucciones particulares que les sean de aplicación establezcan medidas de protección arqueológica deberá realizarse por el promotor de las obras la actividad arqueológica necesaria para la protección del Patrimonio Arqueológico que pudiera existir en el subsuelo.

2. Las actividades arqueológicas que se realicen en cumplimiento del apartado anterior, tendrán el carácter de urgentes, debiendo autorizarse por el procedimiento establecido en el título IV del decreto 32/1993 de 16 de marzo, por el que se aprueba el Reglamento de Actividades arqueológicas.

3. Realizada la actividad arqueológica y evaluados sus resultados, se determinará por el órgano competente para autorizar las obras las previsiones que habrán de incluirse en el proyecto de intervención cuando resulte necesaria la consolidación, integración o renovación del Patrimonio Arqueológico.
4. El proyecto de intervención se presentará una vez redactado conforme a lo previsto en el apartado anterior, acompañado de la documentación a que hace referencia el artículo 47.

\section{Art. 39}

2. A los efectos del reparto de cargas urbanísticas .... se tendrá en cuenta la necesidad de conservación del patrimonio Arqueológico en el momento de estimar los aprovechamientos patrimonializables

Grado de intervención propuesto:

A. Control de movimiento de tierras 9. Remoción general de los substratos. No se considera parte de la obras de edificación sino como un acto de contenido específicamente arqueológico. Sus objetivos son la identificación de elementos estructurales cuya existencia y ubicación no es posible determinar "a priori" y la documentación de la secuencia estratigráfica. Por ello la actuación de las máquinas deberá completarse con los trabajos manuales que requiera el correcta registro de los datos. Comprende un período para el dibujo, toma de mediciones y recogida de materiales identificados.

B. Sondeos.

1. Mecánicos.(S) Parcelas con desarrollo en profundidad entre otras de reciente construcción donde ya se ha producido un vaciado de tierras.

2. Manuales. (S-M) En todos los casos en que aparezcan estructuras distintas de las correspondientes al edificio conservado. Se entiende por estructuras tanto los elementos positivos como negativos (fosas). La aparición de las mismas puede afectar al grado de las parcelas inmediatas.

C. Vigilancia arqueológica. Sobre todo teniendo en cuenta la profundidad a que apareció la sepultura ibero-romana debe existir una vigilancia que controle la posible existencia de restos similares en los niveles mas profundos.

\footnotetext{
9 Control del movimiento de tierras. Registro de los niveles arqueológicamente fértiles mientras se están llevando a cabo los trabajos de excavación sin metodología arqueológica ni finalidad investigadora. No obstante, el ritmo y los medios utilizados para la extracción de tierra debe permitir la correcta documentación de las estructuras inmuebles o unidades de estratificación, así como la recuperación
} de cuantos elementos muebles se consideran de interés. 


\section{APÉNDICE: Diagnóstico de la zona por manzanas}

Tomamos como base los datos incluidos en la memoria del presente Plan Especial:

Calle / número

(Parc.Cat.)

(M2)

(Plantas)

(Conservación)

Cat.PGOU

(Fecha)

Niv.Cat.

Niveles Arqueológicos $\%$

Parcela catastral

Metros cuadrados aproximados de la parcela

Número de plantas de la vivienda

Estado de conservación

$\mathrm{N}^{\circ}$ de ficha en catalogo del P.G.O.U.

Época aproximada de la construcción existente

Catalogación propuesta para la arquitectura

Conocimiento de los contextos arqueológicos

Porcentaje de superficie disponible para

la investigación arqueológica

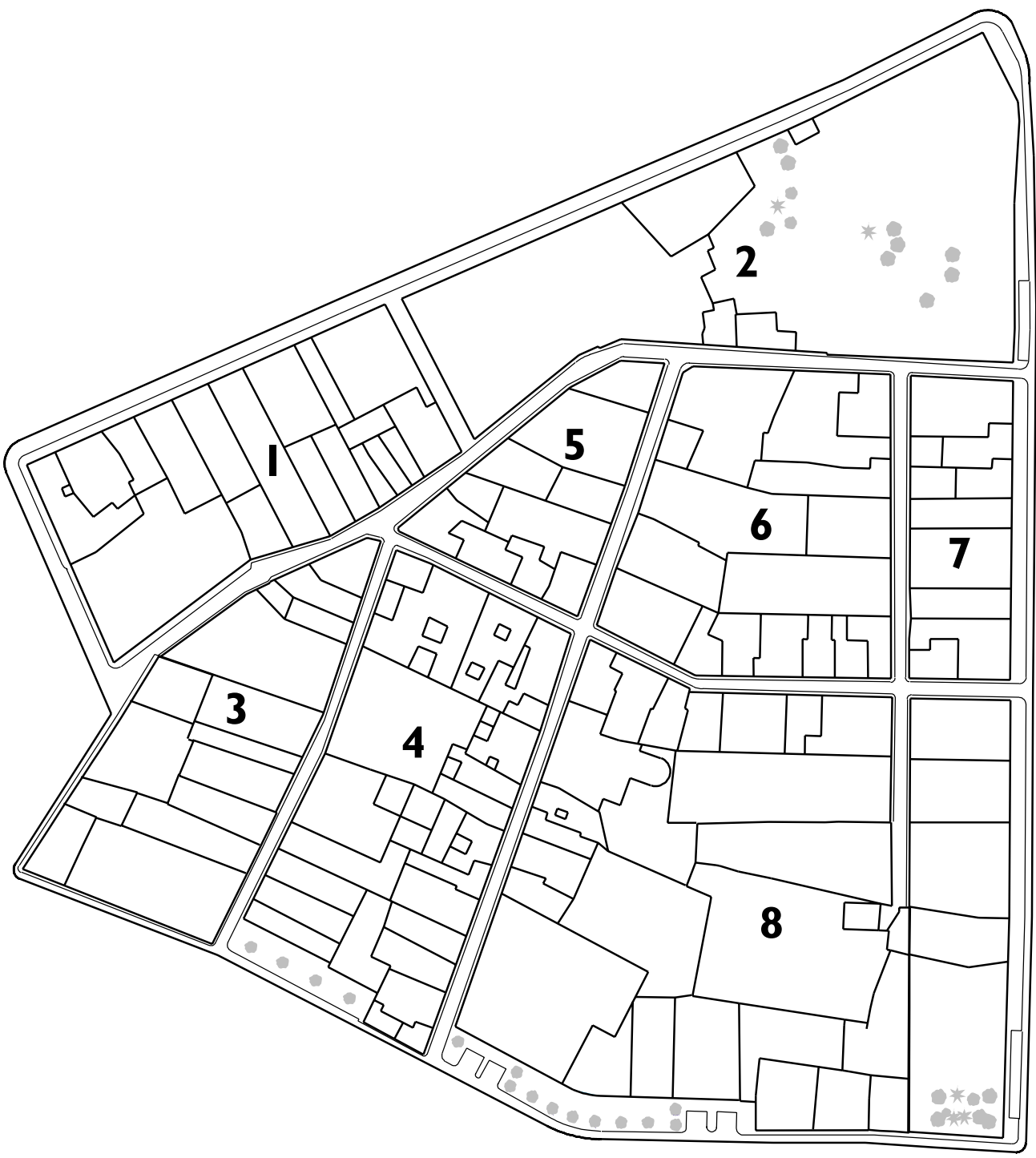

Plano general con la ubicación de las parcelas 
MANZANA I

\begin{tabular}{|l|c|c|c|c|c|c|c|c|c|}
\hline CALLE/NUMERO & $\begin{array}{c}\text { Parc. } \\
\text { Cat. }\end{array}$ & M $^{2}$ & Plantas & Conservación & FECHA & $\begin{array}{c}N^{\circ} \text { Cat. } \\
\text { PGOU }\end{array}$ & $\begin{array}{c}\text { Nivel } \\
\text { Cat }\end{array}$ & $\begin{array}{c}\text { Niveles } \\
\text { Arqueológicos }\end{array}$ & $\begin{array}{c}\% \\
\text { Excav }\end{array}$ \\
\hline Recogidas 13 & 07 & 369 & $8+$ & Bueno & Reciente & - & - & Destruídos & - \\
\hline Frailes 18 & & 315 & $4+$ & Bueno & Reciente & - & - & Destrú́dos & - \\
\hline Frailes 20 & 07 & 52 & 3 & Malo & XIX & - & - & No conocidos & S \\
\hline Frailes 22 & 08 & 52 & 3 & Malo & XIX & - & - & No conocidos & S \\
\hline Frailes 24 & 09 & 143 & $3+$ & Malo & XIX & - & - & No conocidos & S \\
\hline Frailes 24D & 10 & 126 & $3+$ & Malo & XIX & - & - & No conocidos & \\
\hline Frailes 28 & 11 & 135 & 4 & Regular & Reciente & - & - & Destruídos & - \\
\hline Frailes 30 & 12 & & & Bueno & Reciente & - & - & Destruídos & - \\
\hline Martín Lagos 3 & 12 & 860 & 6 & Bueno & Reciente & - & - & Destruídos & - \\
\hline Martín Lagos 1 & 13 & 265 & 8 & Bueno & Reciente & - & - & Destruídos & - \\
\hline Recogidas 27 & 13 & 212 & $8+$ & Regular & Reciente & - & - & Destruídos & - \\
\hline Recogidas 25 & 15 & 120 & 5 & Regular & Reciente & - & - & Destruídos & - \\
\hline Recogidas 23 & 16 & 237 & $5+$ & Regular & Reciente & - & - & Destruídos & - \\
\hline Recogidas 21 & 17 & 238 & $7+$ & Regular & Reciente & - & - & Destruídos & - \\
\hline Recogidas 19 & & 360 & $6+$ & Bueno & Reciente & - & - & Destruídos & - \\
\hline Recogidas 17 & 18 & 250 & 4 & Bueno & Reciente & - & - & Destruídos & - \\
\hline Recogidas 15 & 19 & 84 & 6 & Bueno & Reciente & - & - & Destruídos & - \\
\hline
\end{tabular}

Delimitada por las calles Recogidas, Martin Lagos, Pegarrecio y Frailes.

Las únicas parcelas cuyo substrato arqueológico no ha sido destruido en su totalidad tienen construcciones en profundidad muy estrechas inmediatas a la calle Frailes. Por sus características apenas permiten un sondeo longitudinal que establezca la posible correspondencia con un camino o la acequia que da lugar a la calle.

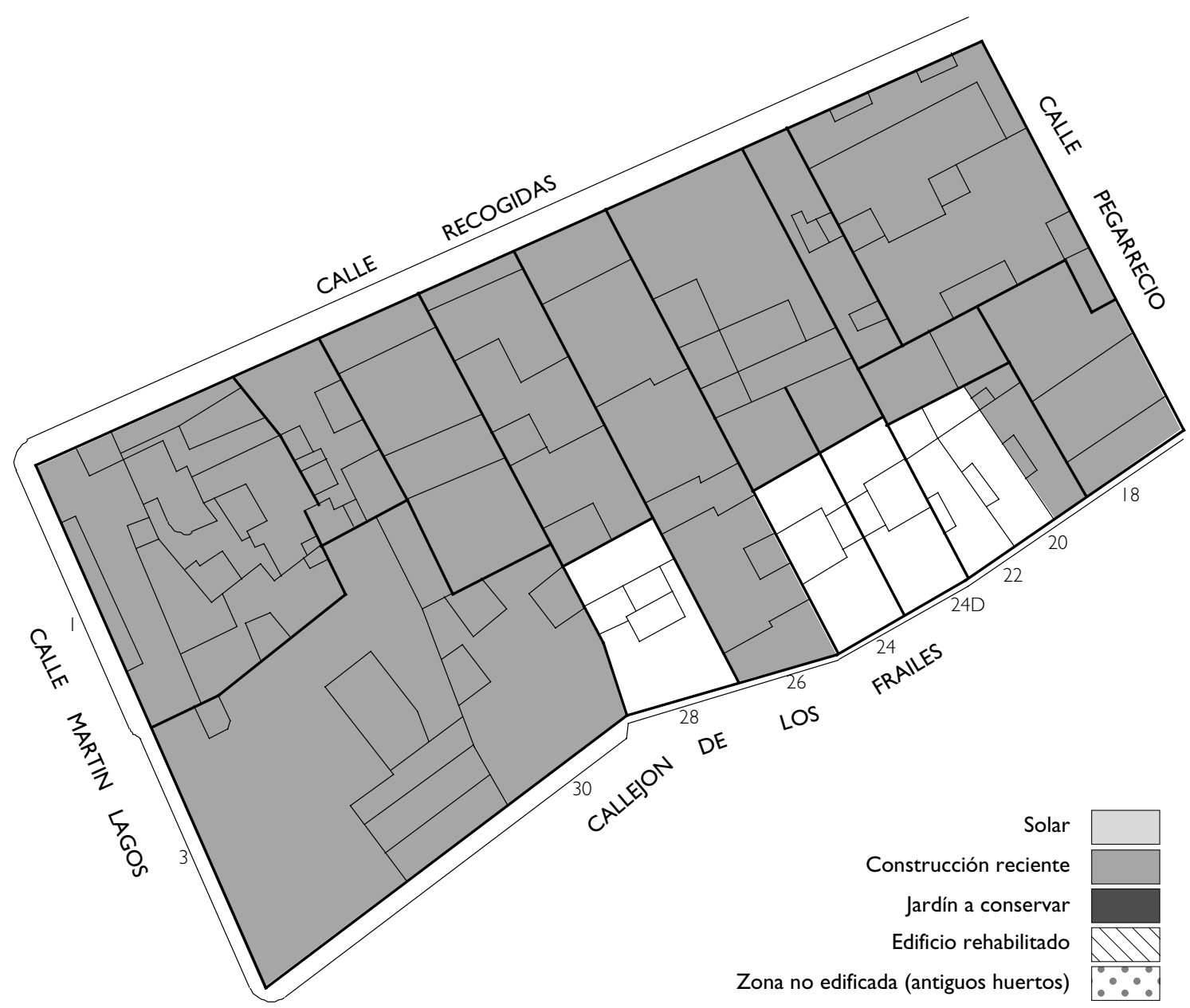


MANZANA 2

\begin{tabular}{|l|c|c|c|c|c|c|c|c|c|}
\hline CALLE/NUMERO & $\begin{array}{c}\text { Parc. } \\
\text { Cat. }\end{array}$ & M $^{2}$ & Plantas & Conservación & FECHA & $\begin{array}{c}N^{\circ} \text { Cat. } \\
\text { PGOU }\end{array}$ & $\begin{array}{c}\text { Nivel } \\
\text { Cat }\end{array}$ & $\begin{array}{c}\text { Niveles } \\
\text { Arqueológicos }\end{array}$ & $\begin{array}{c}\% \\
\text { Excav }\end{array}$ \\
\hline Frailes 4-6 & 03 & 88 & $3 / 4$ & Regular & XIX & - & - & No conocidos & S-M \\
\hline Frailes 8 & 04 & 67 & $3+$ & Bueno & XIX & - & - & No conocidos & S-M \\
\hline Recogidas 9-II & 05 & 1.896 & 7 & Bueno & Reciente & - & - & Destruídos & - \\
\hline Recogidas 7 & 06 & 334 & 7 & Bueno & Reciente & - & - & Destruídos & - \\
\hline Recogidas 5 & 02 & 3.930 & - & Regular & S.XVII & - & BIC & No conocidos & - \\
\hline Recogidas 3 & 01 & 21 & 2 & Bueno & & - & - & No conocidos & \\
\hline
\end{tabular}

Delimitada por las calles Recogidas, San Antón, Frailes y Pegarrecio.

Corresponde al convento de San Antón. Sólo conserva unas pequeñas parcelas en la calle Frailes. De ser correctas las hipótesis planteadas, corresponderían a un segundo momento, cuando se cierra el pasillo que separa la manzana originada por el eje de la calle Recogidas del Convento de San Antón, debido a que la infraestructura hidráulica que obliga a conservar dicho espacio sin edificar y da lugar a la calle Frailes se encuentra en desuso. Por su relación con dicha infraestructura funcional es interesante la verificación del proceso mediante excavación.

La escasa superficie disponible reduce la intervención a sondeos puntuales, siendo aconsejable el control posterior del movimiento de tierras.

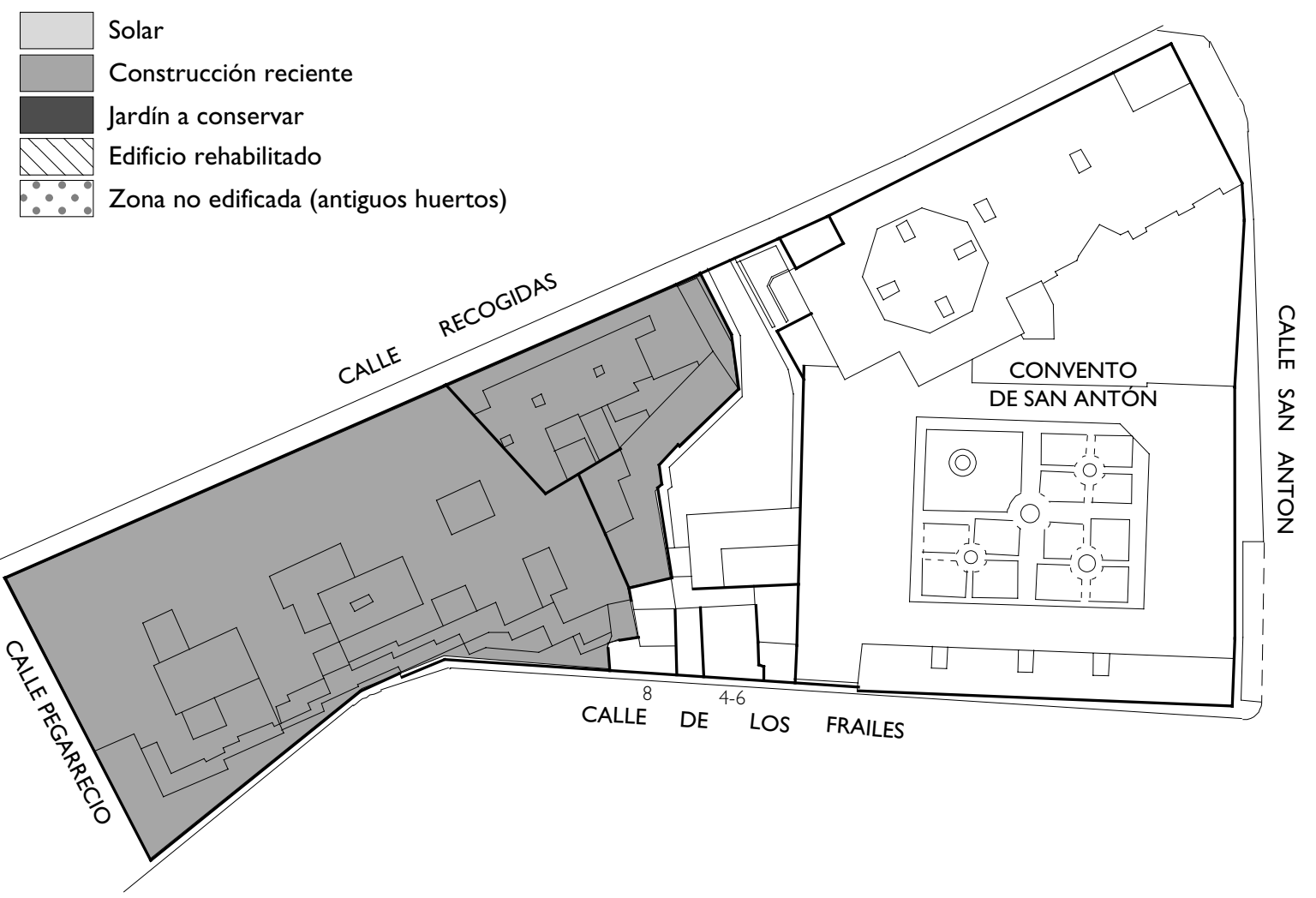


MANZANA 3

\begin{tabular}{|l|c|c|c|c|c|c|c|c|c|}
\hline CALLE/NUMERO & $\begin{array}{l}\text { Parc. } \\
\text { Cat. }\end{array}$ & M $^{2}$ & Plantas & Conservación & FECHA & $\begin{array}{c}\text { N }^{\circ} \text { Cat. } \\
\text { PGOU }\end{array}$ & $\begin{array}{c}\text { Nivel } \\
\text { Cat }\end{array}$ & $\begin{array}{c}\text { Niveles } \\
\text { Arqueológicos }\end{array}$ & $\begin{array}{c}\% \\
\text { Excav }\end{array}$ \\
\hline Afan de Rivera 2 & 01 & 112 & 3 & Bueno & XIX & - & - & Destruídos & - \\
\hline Afan de Rivera 4 & 02 & 108 & 3 & rehabilitada & XIX & - & - & No conocidos & \\
\hline Afan de Rivera 6 & 03 & 75 & $3 / 4$ & Regular & XIX & - & - & No conocidos & \\
\hline Afan de Rivera 12 & 05 & 286 & 3 & Regular & XVIII & 838 & A & No conocidos & S \\
\hline Afan de Rivera 14 & 06 & 104 & 3 & Bueno & Reciente & - & - & Destruídos & - \\
\hline Afan de Rivera 16 & 07 & 204 & 5 & Bueno & Reciente & - & - & No conocidos & 50 \\
\hline Afan de Rivera 18 & 08 & 177 & - & Solar & - & - & - & No conocidos & 50 \\
\hline Afan de Rivera 20 & 09 & 235 & - & Solar & - & - & - & No conocidos & 60 \\
\hline Afan de Rivera 22 & 10 & 621 & $3+$ & Malo & XVII-XVIII & - & A & No conocidos & 65 \\
\hline Porton Tejeiro 7 & 11 & 99 & - & Solar & - & - & - & No conocidos & 45 \\
\hline P. Tejeiro 5 Dupl & 12 & 57 & - & Solar & - & - & - & No conocidos & 65 \\
\hline Porton Tejeiro 5 & 13 & 105 & - & Solar & - & - & - & No conocidos & 50 \\
\hline P. Tejeiro 3 Dupl & 14 & 136 & $3 / 4$ & Malo & XIX & - & - & No conocidos & 50 \\
\hline Porton Tejeiro 3 & 15 & 151 & $3 / 4$ & Malo & XIX & - & - & No conocidos & 50 \\
\hline Porton Tejeiro 1 & 17 & 161 & $3+$ & Regular & XIX & - & - & No conocidos & 50 \\
\hline Frailes 25 & 18 & 33 & 3 & Bueno & Reciente & - & - & No conocidos & - \\
\hline Frailes 27 & 04 & 566 & 3 & Bueno & Reciente & - & - & No conocidos & - \\
\hline
\end{tabular}

Delimitada por las calles Frailes, Portón de Tejeiro, Nueva de S. Antón y Afan de Ribera.

Contiene una de los edificios mas antiguos de la zona, la casa de Afan de Ribera, que puede pertenecer al momento preurbano, lo que constituye una interesante referencia para determinar la organización espacial en dicho momento.

En la zona aún no consolidada existen parcelas estrechas organizadas en profundidad. Construcciones en mal estado de conservación o ya solares.

Según las hipótesis propuestas correspondería a una parcelación sistemática sobre el parcelario rural. La casa de Afan de Ribera podría ser el edificio dominante correspondiente a la parcela agrícola por lo que no parece probable que existan otras edificaciones pertenecientes a distintas propiedades en su entorno. El entorno correspondiente a la calle Frailes y la posible acequia principal de la zona se encuentra consolidado. Se propone el control de movimiento de tierras.
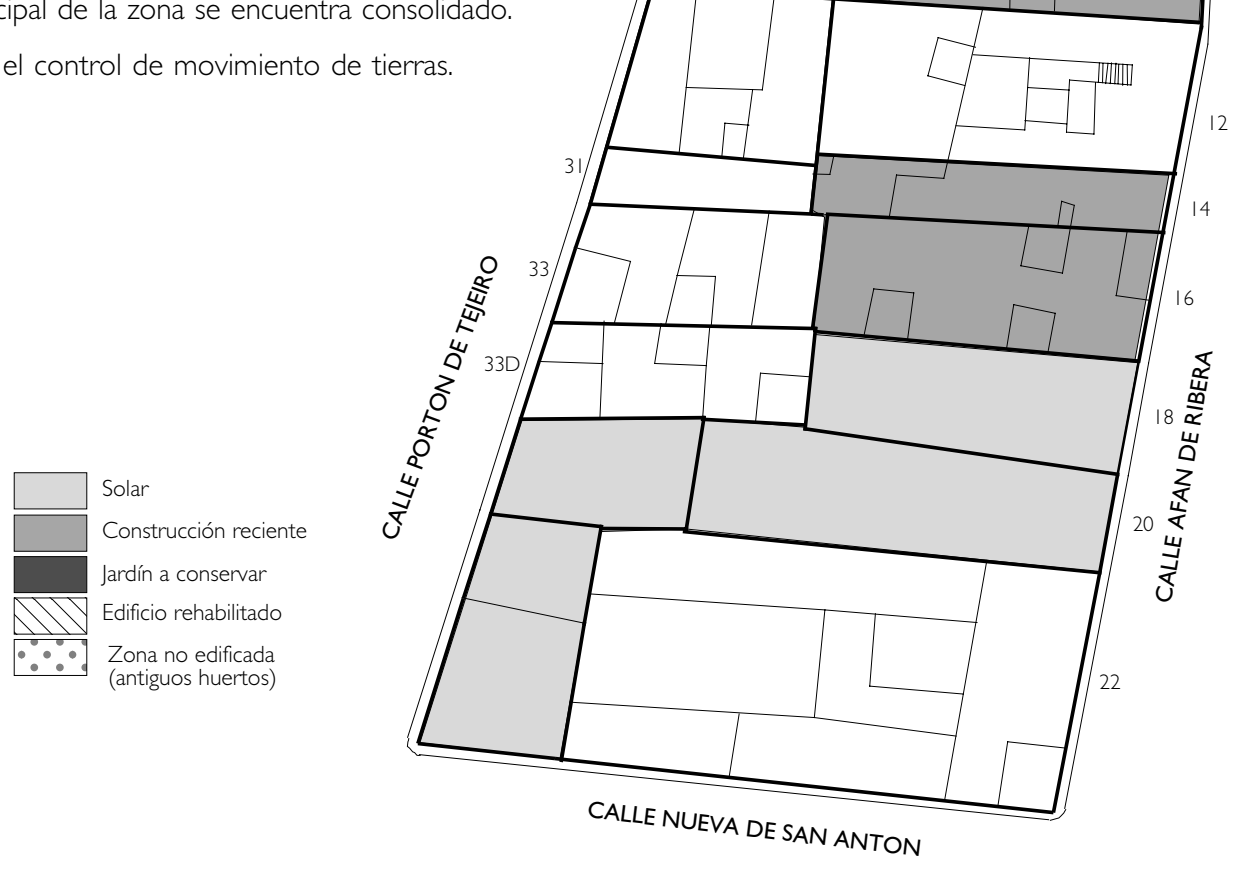
MANZANA 4

\begin{tabular}{|c|c|c|c|c|c|c|c|c|c|}
\hline CALLE/NUMERO & $\begin{array}{l}\text { Parc. } \\
\text { Cat. }\end{array}$ & $M^{2}$ & Plantas & Conservación & FECHA & $\begin{array}{l}N^{\circ} \text { Cat. } \\
\text { PGOU }\end{array}$ & $\begin{array}{c}\text { Nivel } \\
\text { Cat }\end{array}$ & $\begin{array}{c}\text { Niveles } \\
\text { Arqueológicos }\end{array}$ & $\begin{array}{c}\% \\
\text { Excav }\end{array}$ \\
\hline Afan de Ribera I & 01 & 63 & 4 & rehabilitada & $X I X-X X$ & 840 & B & No conocidos & 45 \\
\hline Horno Espadero 21 & 02 & 428 & $4 / 2$ & Solar & - & - & - & No conocidos & 65 \\
\hline Horno Espadero 19 & 03 & 226 & $4+$ & Bueno & Reciente & - & - & Destruídos & - \\
\hline S. Jose Baja 12 & 04 & 225 & 3 & Regular & XIX & - & $\mathrm{B}$ & No conocidos & 60 \\
\hline S. Jose Baja 14 & 05 & 48 & $3 / 4$ & rehabilitada & $\mathrm{XIX}-\mathrm{XX}$ & 858 & $B$ & No conocidos & S-M \\
\hline S. Jose Baja 16 & 06 & 175 & $3+$ & Regular & $X I X-X X$ & 859 & $\mathrm{~B}$ & Sótano & 50 \\
\hline S. Jose Baja 18 & 07 & 110 & 3 & Mala & $\mathrm{XIX}$ & 860 & $B$ & No conocidos & 50 \\
\hline S. Jose Baja 20 & 08 & 99 & 3 & Mala & $X I X-X X$ & 861 & $\mathrm{~B}$ & No conocidos & 45 \\
\hline S. Jose Baja 22 & 09 & 283 & $2 / 3$ & rehabilitada & $X V I I I-X I X$ & 862 & B & No conocidos & 60 \\
\hline S. Jose Baja 24 & 10 & 80 & 4 & rehabilitada & $X I X-X X$ & 863 & B & No conocidos & 45 \\
\hline S. Jose Baja 26 & 11 & 165 & 3 & Solar & $X V I I-X V I I I$ & 864 & B & No conocidos & 50 \\
\hline S. Jose Baja 28 & 12 & 117 & 3 & Regular & $X V I I I$ & 865 & $\mathrm{~B}$ & No conocidos & 50 \\
\hline S. Jose Baja 30 & 13 & 130 & 3 & rehabilitada & $X I X-X X$ & 866 & B & No conocidos & 50 \\
\hline S. Jose Baja 32 & 14 & 131 & $4 / 3$ & rehabilitada & $\mathrm{XIX-XX}$ & - & B & No conocidos & 50 \\
\hline S. Jose Baja 34 & 15 & 32 & 3 & Regular & $\mathrm{XVIII-XIX}$ & - & - & No conocidos & S-M \\
\hline Nueva S. Antón 18 & 16 & 35 & - & Ruina & $\mathrm{XVIII-XIX}$ & - & - & No conocidos & S-M \\
\hline Nueva S. Antón 20 & 17 & 166 & $6 / 7$ & Bueno & reciente & - & - & Destruídos & - \\
\hline Nueva S. Antón 22 & 18 & 99 & 6 & Bueno & reciente & - & - & Destruídos & - \\
\hline Afan Riv. 13/15/17 & $|9-2|$ & 497 & - & Solar & - & - & - & No conocidos & 65 \\
\hline Afan de Rivera II & 22 & 286 & $3 / 2$ & Buena & reciente & - & - & Destruídos & - \\
\hline Afan de Rivera 9/7 & 23 & 516 & $3 / 4$ & Buena & reciente & - & - & Destruídos & - \\
\hline Afan de Rivera 3 & 24 & 32 & 3 & rehabilitada & reciente & 841 & B & Sótano & S-M \\
\hline
\end{tabular}

Delimitada por las calles Horno de Espadero, Afan de Ribera, Nueva de S. Antón y S. José Baja.

Su borde inferior ha sido afectado en su mayor parte por el ensanche de la calle Nueva de S. Antón. Manzana con parcelario muy regular delimitando diez grandes unidades sensiblemente cuadradas, que posteriormente han sido subdivididas de forma mas irregular. Evidencia una organización programada cuyas edificaciones originales han sido destruidas en su totalidad en el lado de la calle Afan de Ribera.

La posible correspondencia de la calle S. José Baja con un ramal de la acequia que origina la calle Frailes hace de aquella un elemento especial de referencia para la delimitación del parcelario agrícola y la posible ubicación de construcciones en su borde, por ello no es extraño que conserve las tipologías mas antiguas edificadas. En su borde superior, la toponimia de la calle: Horno de Espadero, revela la presencia de unos usos en el nuevo barrio.

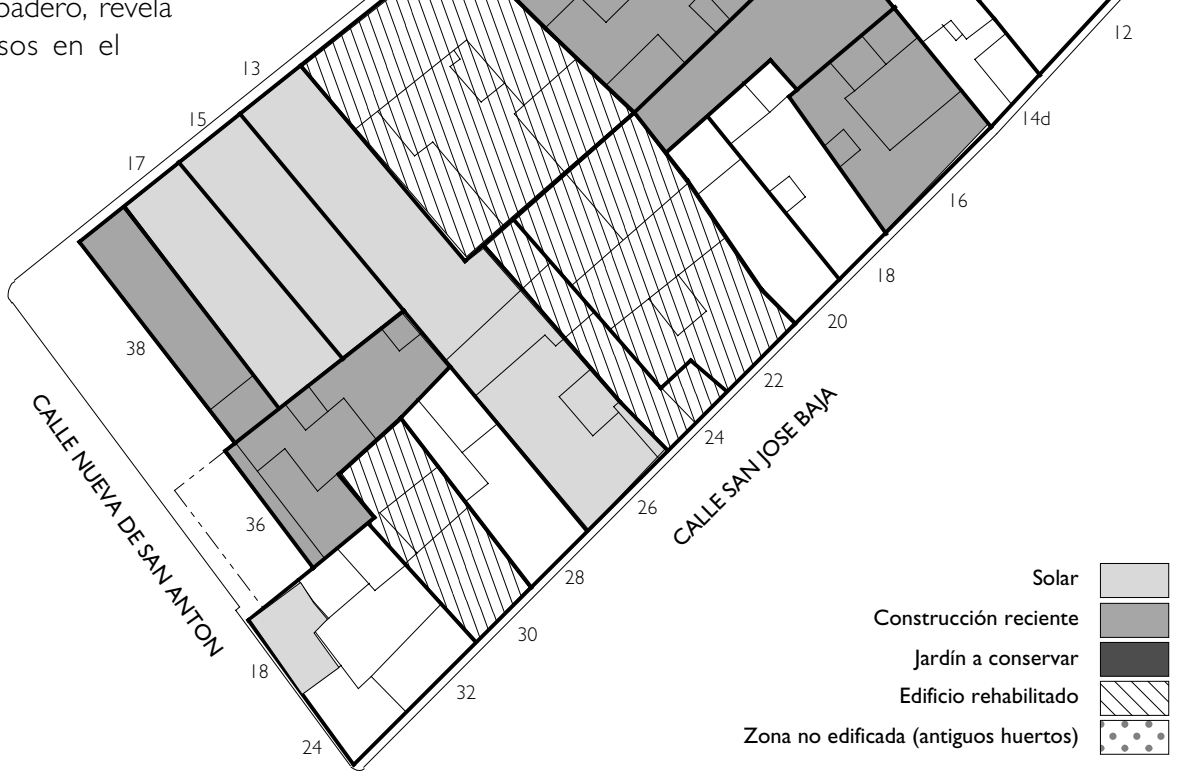


MANZANA 5

\begin{tabular}{|l|c|c|c|c|c|c|c|c|c|}
\hline CALLE/NUMERO & $\begin{array}{c}\text { Parc. } \\
\text { Cat. }\end{array}$ & M $^{2}$ & Plantas & Conservación & FECHA & $\begin{array}{c}\text { N }^{\circ} \text { Cat. } \\
\text { PGOU }\end{array}$ & $\begin{array}{c}\text { Nivel } \\
\text { Cat }\end{array}$ & $\begin{array}{c}\text { Niveles } \\
\text { Arqueológicos }\end{array}$ & $\begin{array}{c}\% \\
\text { Excav }\end{array}$ \\
\hline S. Jose Baja 2 & 01 & 142 & 3 & Regular & XIX-XX & - & - & No conocidos & 50 \\
\hline S. Jose Baja 4 & 02 & 394 & $4+$ & Regular & XIX-XX & - & B & No conocidos & 65 \\
\hline S. Jose Baja 6 & 03 & 135 & $3 / 4$ & Regular & XIX & - & - & No conocidos & 50 \\
\hline S. Jose Baja 8 & 04 & 262 & 3 & rehabilitada & XVIII-XIX & 848 & B & No conocidos & 60 \\
\hline S. Jose Baja 10 & 05 & 102 & 3 & rehabilitada & XX & 847 & B & No conocidos & 50 \\
\hline Horno Espadero 22 & 06 & 84 & 3 & Solar & - & 850 & - & No conocidos & 45 \\
\hline Horno Espadero 24 & 07 & 115 & 4 & Bueno & reciente & - & - & Destruídos & - \\
\hline Frailes 17 & 08 & 136 & $3 / 4$ & Bueno & reciente & 843 & B & $?$ & - \\
\hline Frailes 15 & 09 & 77 & 4 & Bueno & reciente & - & - & Destruídos & - \\
\hline Frailes 13 & 10 & 160 & $3 / 4$ & rehabilitada & XIX & - & B & No conocidos & 55 \\
\hline
\end{tabular}

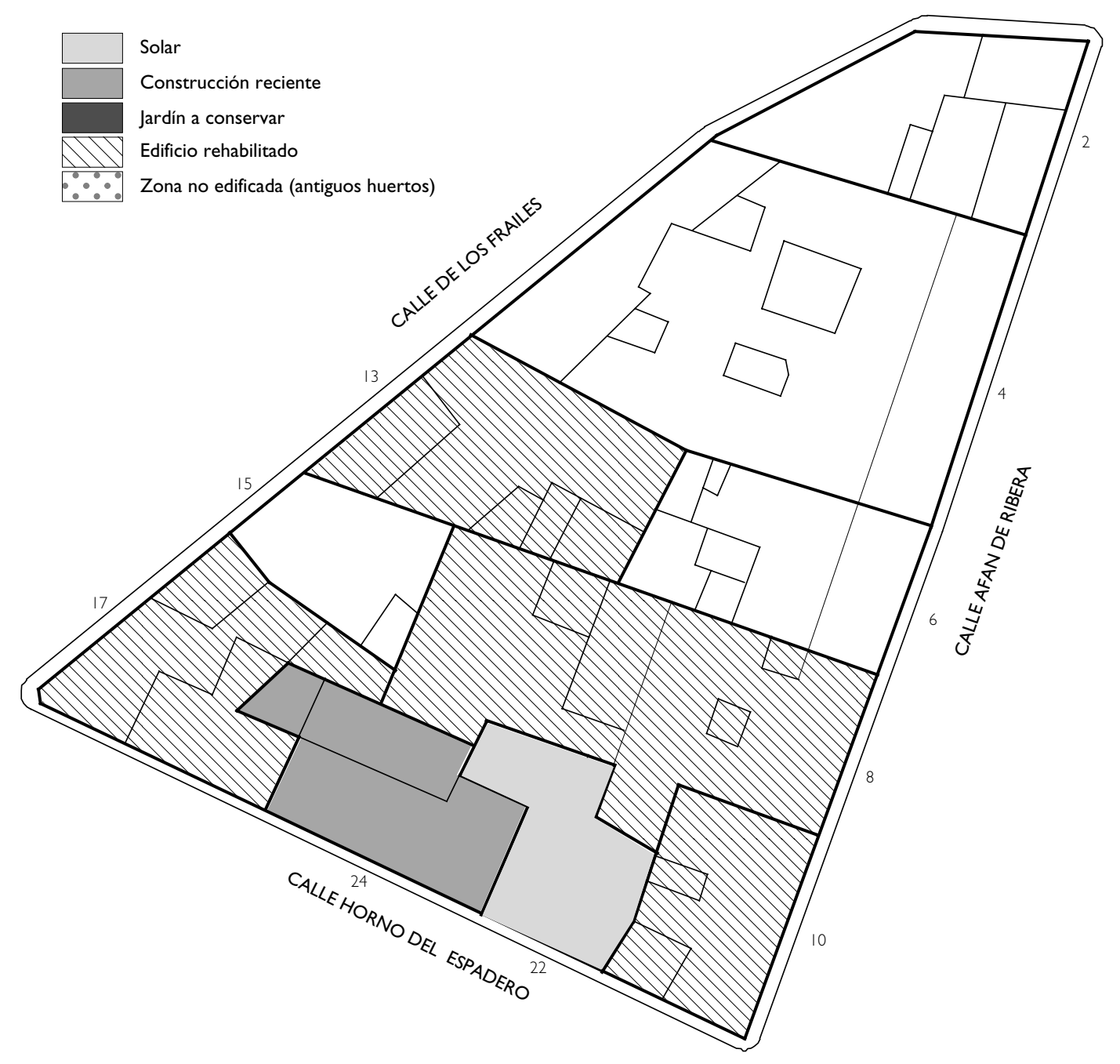


MANZANA 6

\begin{tabular}{|c|c|c|c|c|c|c|c|c|c|}
\hline CALLE/NUMERO & $\begin{array}{l}\text { Parc. } \\
\text { Cat. }\end{array}$ & $M^{2}$ & Plantas & Conservación & FECHA & $\begin{array}{l}N^{\circ} \mathrm{Cat} . \\
\text { PGOU }\end{array}$ & $\begin{array}{c}\text { Nivel } \\
\text { Cat }\end{array}$ & $\begin{array}{c}\text { Niveles } \\
\text { Arqueológicos }\end{array}$ & $\begin{array}{c}\% \\
\text { Excav }\end{array}$ \\
\hline Frailes 7 & 01 & 470 & 5 & Bueno & Reciente & - & - & Destruídos & - \\
\hline Frailes 5 & 02 & 248 & $3 / 4$ & Bueno & Reciente & - & - & No conocidos & \\
\hline Padre Alcover 2 & 03 & 152 & $3 / 4$ & rehabilitada & $X V I I I-X I X$ & - & - & No conocidos & $\mathrm{S}-50$ \\
\hline Padre Alcover 4 & & 133 & 3 & Bueno & Reciente & - & - & No conocidos & \\
\hline Padre Alcover 6 & 04 & 210 & 3 & Bueno & XIX & - & - & No conocidos & $S-60$ \\
\hline Padre Alcover 8 & 05 & 256 & 4 & Bueno & $\mathrm{XVIII}$ & 856 & A & No conocidos & 60 \\
\hline Padre Alcover 10 & 06 & 513 & 3 & Malo & $\mathrm{XVIII/XIX}$ & 855 & A & No conocidos & 65 \\
\hline Padre Alcover 12 & 07 & 97 & $4 / 5$ & rehabilitada & Reciente & - & - & No conocidos & \\
\hline Horno Espadero 8 & 08 & 72 & $3 / 4$ & rehabilitada & XIX & 851 & $B$ & No conocidos & 45 \\
\hline Horno Espadero 10 & 09 & 81 & $3 / 4$ & Regular & $\mathrm{XIX}$ & - & $B$ & No conocidos & 45 \\
\hline Horno Espadero 12 & 10 & 144 & $3 / 4$ & rehabilitada & $X I X$ & - & - & No conocidos & 50 \\
\hline Horno Espadero 14 & 11 & 122 & $3 / 4$ & rehabilitada & $\mathrm{XVIII}$ & 854 & $\mathrm{~B}$ & No conocidos & 50 \\
\hline Horno Espadero 16 & 12 & 98 & $4 / 5$ & Bueno & reciente & - & - & Destruídos & - \\
\hline Horno Espadero 18 & 13 & 294 & $4 / 5$ & Bueno & reciente & - & - & Destruídos & - \\
\hline S. Jose Baja 7 & 14 & 310 & 36 & Malo & XIX & - & - & No conocidos & S- \\
\hline S. Jose Baja 5 & 15 & 465 & $4 / 5$ & Regular & reciente & - & - & Destruídos & - \\
\hline S. Jose Baja 3 & 16 & 80 & $3+$ & rehabilitada & XIX & - & - & No conocidos & S- \\
\hline
\end{tabular}

Junto con la manzana 8 definen una gran cuña que forma el núcleo de la zona. Son las dos unidades donde menos impacto tuvo el proceso de urbanización, mostrando, a nuestro parecer, que el mismo se produjo de forma paulatina desde los bordes hacia el interior, articulados mediantes elementos espaciales rurales.

Consolidada la arquitectura en la calle S. José Baja, salvo una parcela, queda la zona correspondiente a la Calle Padre Alcover y Horno de Espadero, con tipologías entre las mas antiguas de la zona e incluso un corral de vecinos que sabe aprovechar el fondo de la manzana. La forma ligeramente en cuña es salvada mediante la articulación de las parcelas en relación a las calles inmediatas y una organización en profundidad.

No obstante la irregularidad de la parcelas, tanto en su tamaño como en su perímetro, parece indicar la adaptación a un espacio ya dado, no originado por el diseño de una trama urbana regular. La continuidad con la manzana 8 muestra que la calle S.José Baja sería el eje de referencia inicial mientras que la calle Padre Alcover es un intento de articular las manzanas en base a la edificación de borde de la calle S. Antón.

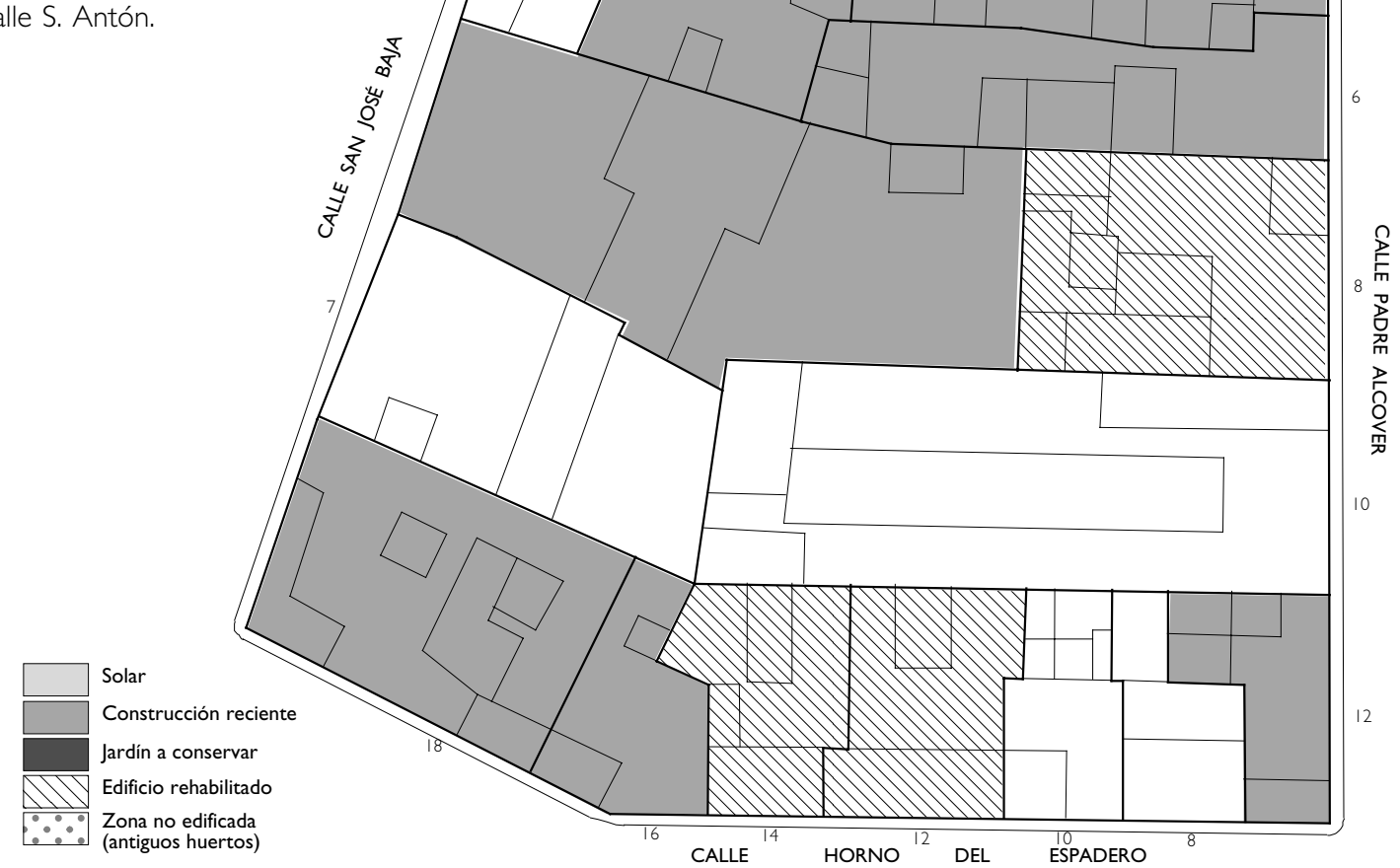


MANZANA 7

\begin{tabular}{|l|c|c|c|c|c|c|c|c|c|}
\hline CALLE/NUMERO & $\begin{array}{c}\text { Parc. } \\
\text { Cat. }\end{array}$ & $M^{2}$ & Plantas & Conservación & FECHA & $\begin{array}{c}N^{\circ} \text { Cat. } \\
\text { PGOU }\end{array}$ & $\begin{array}{c}\text { Nivel } \\
\text { Cat }\end{array}$ & $\begin{array}{c}\text { Niveles } \\
\text { Arqueológicos }\end{array}$ & $\begin{array}{c}\% \\
\text { Excav }\end{array}$ \\
\hline S. Anton 16 & 01 & 226 & $4 / 3$ & Bueno & $X X$ & - & B & No conocidos & 60 \\
\hline S. Anton 14 & 02 & 157 & $5 / 3$ & Bueno & $X X$ & - & B & No conocidos & 50 \\
\hline S. Anton 12 & 03 & 302 & $6 / 5 / 4$ & Bueno & reciente & - & - & Destruídos & - \\
\hline S. Anton 10 & 04 & 149 & $7 / 6 / 5$ & Bueno & reciente & - & - & Destruídos & - \\
\hline S. Anton 8 & 05 & 95 & $4 / 5$ & Regular & $X X$ & - & B & No conocidos & 45 \\
\hline S. Anton 6 & 06 & 117 & 5 & Regular & $X X$ & - & B & No conocidos & 50 \\
\hline S. Anton 4 & 07 & 295 & 6 & Bueno & reciente & - & - & Destruídos & - \\
\hline Padre Alcover 3 & 08 & 49 & 2 & Bueno & XVII-XIX & - & - & No conocidos & S \\
\hline Padre Alcover 5 & 09 & 73 & $2 / 3$ & Solar en construcción - & - & No conocidos & 45 \\
\hline Horno Espadero 4 & 10 & 90 & $3 / 4$ & Regular & XIX-XX & - & B & No conocidos & 45 \\
\hline
\end{tabular}

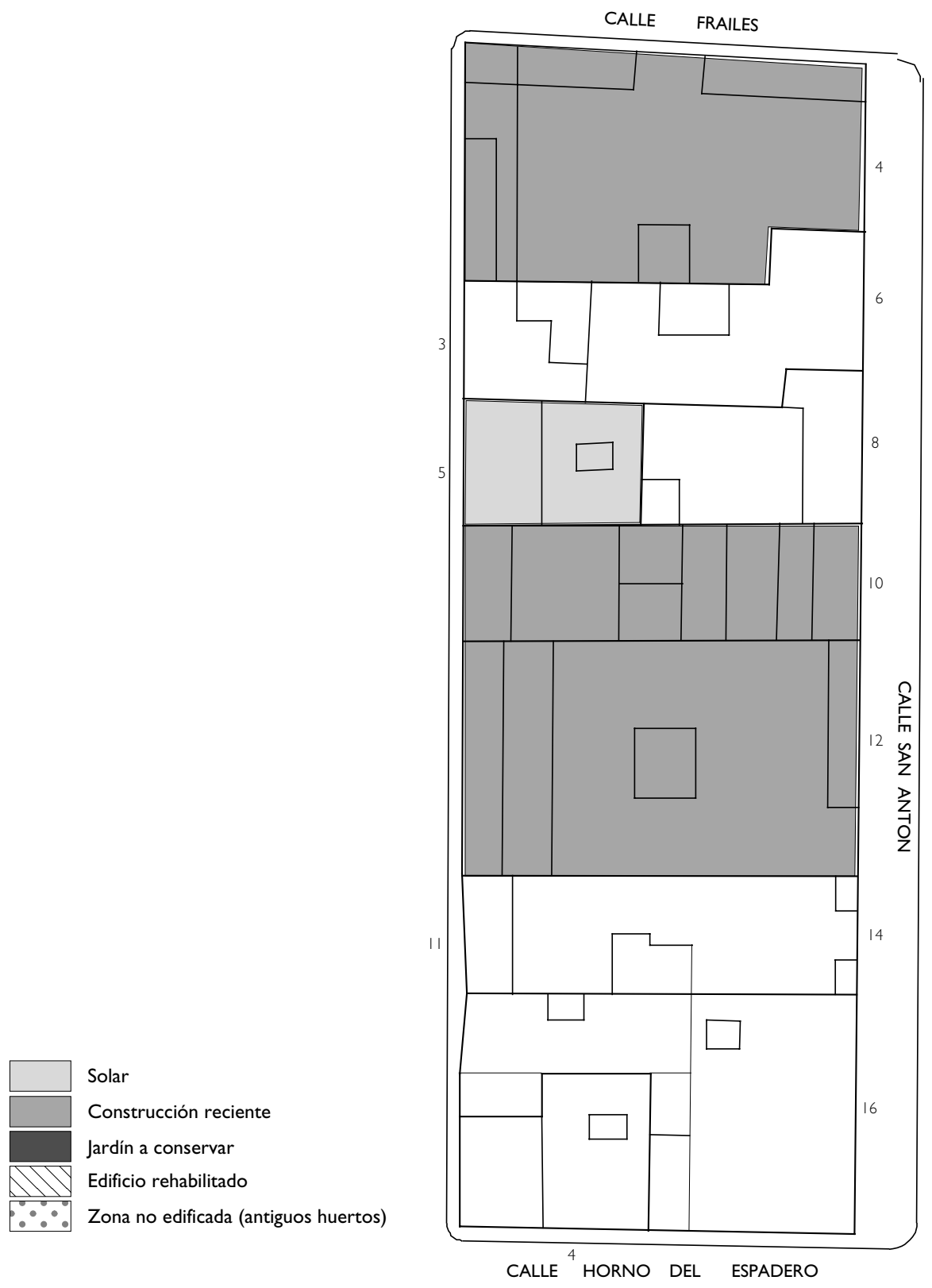


MANZANA 8

\begin{tabular}{|c|c|c|c|c|c|c|c|c|c|}
\hline CALLE/NUMERO & $\begin{array}{l}\text { Parc. } \\
\text { Cat. }\end{array}$ & $M^{2}$ & Plantas & Conservación & FECHA & $\begin{array}{l}N^{\circ} \mathrm{Cat} . \\
\text { PGOU }\end{array}$ & $\begin{array}{c}\text { Nivel } \\
\text { Cat }\end{array}$ & $\begin{array}{c}\text { Niveles } \\
\text { Arqueológicos }\end{array}$ & $\begin{array}{c}\% \\
\text { Excav }\end{array}$ \\
\hline Horno Espadero 15 & 01 & 116 & 2 & Bueno & reciente & & - & & - \\
\hline Horno Espadero 13 & 02 & 171 & $2 / 3$ & rehabilitada & $X I X-X X$ & & $\mathrm{~B}$ & No conocidos & 50 \\
\hline Horno Espadero II & 03 & 120 & 3 & Regular & XIX & & $B$ & No conocidos & 50 \\
\hline Horno Espadero 9 & 04 & 106 & 2 & abandono & $\mathrm{XVIII-XIX}$ & & - & No conocidos & 50 \\
\hline Horno Espadero 7 & 05 & 199 & 2 & Regular & $X V I I I-X I X$ & & - & No conocidos & 50 \\
\hline Horno Espadero 5 & 06 & 88 & 3 & Regular & $X I X-X X$ & & - & No conocidos & 45 \\
\hline Horno Espadero 3 & 07 & 218 & 3 & rehabilitada & $X I X-X X$ & & - & No conocidos & 60 \\
\hline S. Anton 18 & 08 & 297 & $5 / 6 / 7$ & Bueno & reciente & & - & Destruídos & - \\
\hline S. Anton 20 & 09 & 315 & $2 / 3$ & rehabilitada & $X \mid X-X X$ & & $B$ & No conocidos & S-65 \\
\hline S. Anton 22/24 & 10 & 472 & $3 / 4$ & Bueno & reciente & & - & Destruídos & - \\
\hline S. Anton 26 & 11 & 266 & $6 / 7$ & Bueno & reciente & & - & Destruídos & - \\
\hline S. Anton 28 & 12 & 1.242 & 3 & Regular & $\mathrm{XIX}$ & 949 & A & No conocidos & 65 \\
\hline Nueva S. Anton 4 & 13 & 148 & $4+$ & Regular & solar & - & - & No conocidos & 50 \\
\hline Nueva S. Anton 6 & 14 & 220 & 4 & Regular & solar & - & - & No conocidos & 60 \\
\hline Nueva S. Anton 8 & 15 & 315 & - & solar & - & - & - & No conocidos & 65 \\
\hline Nueva S. Anton 10 & 16 & 315 & $6 / 7$ & Bueno & reciente & - & - & Destruídos & - \\
\hline Nueva S. Anton 12 & 17 & 220 & $6 / 7$ & Bueno & reciente & - & - & Destruídos & - \\
\hline Nueva S. Anton 14 & 18 & 188 & 6 & Bueno & $X X$ & - & - & & - \\
\hline Nueva S. Anton 16 & 19 & 1.020 & $6 / 3$ & Bueno & reciente & - & - & Destruídos & - \\
\hline S. Jose Baja 21 & 20 & 102 & 3 & rehabilitada & XIX & 872 & $B$ & & 50 \\
\hline S. Jose Baja 19 & 21 & 138 & 3 & Regular hostal & $\mathrm{XIX}$ & 871 & $B$ & & 50 \\
\hline S. Jose Baja 17 & 22 & 752 & 3 & rehabilitada & $\mathrm{XVIII-XIX|}$ & 870 & $\mathrm{~B}$ & & 65 \\
\hline S. Jose Baja 15 & 23 & 112 & 3 & rehabilitada & $\mathrm{XVIII-XIX|}$ & 869 & $B$ & & 50 \\
\hline S. Jose Baja 13 & 24 & 560 & $3 / 2$ & rehabilitada & $X I X-X X$ & 868 & $\mathrm{~B}$ & & 65 \\
\hline Padre Alcover 16 & 25 & 710 & $3 / 1$ & Regular & $X \mid X-(X V|I| ?)$ & - & - & & 65 \\
\hline Padre Alcover 18/20 & 26 & 611 & - & solar & - & - & - & & 65 \\
\hline Padre Alcover 22 & 27 & 49 & - & solar & - & - & $S$ & No conocidos & $S$ \\
\hline Padre Alcover s/n & 28 & 1.128 & 1 & solar & - & - & $\mathrm{S}$ & No conocidos & \\
\hline Padre Alcover 19 & & & & abandono & & - & - & No conocidos & \\
\hline
\end{tabular}

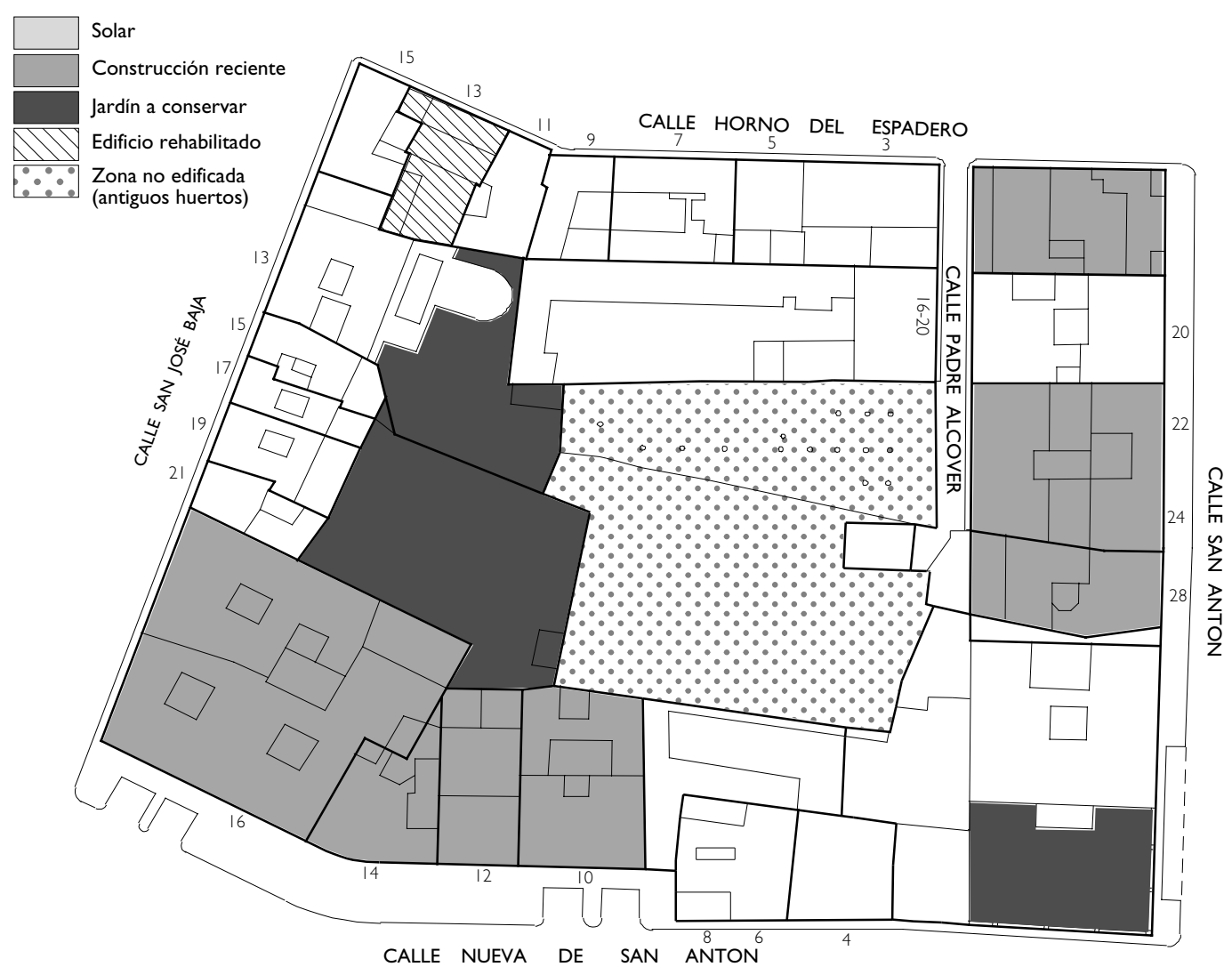




\section{RESUMEN}

Se presenta el trabajo realizado para el Plan Especial de Protección y Reforma interior del barrio de San Antón (Granada). En la primera parte se analiza el proceso de configuración espacial en base a preexistencia de naturaleza rural, el carácter de trama urbana no consolidada y su relación con los distintos momentos históricos. En la segunda se establece un diagnóstico de su potencialidad arqueológica en función de la arquitectura del barrio y el proceso histórico criterios de normativa deducibles de sus características históricas y morfológicas.

PALABRAS CLAVE: Planeamiento urbanístico, Granada, Diagnóstico arqueológico, San Antón

\section{ABSTRACT}

We present here the study carried out for the Special Plan of Protection and Inner Reform of District S. Antón (Granada). In the first section we analyze the way spaces are configurated on the basis of rural preexistent features, the zone's character of non-consolidated urban pattern and its relation with different historical moments. In the second we establish a diagnosis of its archaeological potentiality according to district architecture and historical process, and define some criteria for legal regulations derived from historical and morphologic characteristics.

PALABRAS CLAVE: Town planning, Granada, archaeological diagnosis, San Antón 
Puente del Genil Huertas del Jaragüi Río Darro I. De S. Antón Carrrera de la Virgen Castillo Bibataubín

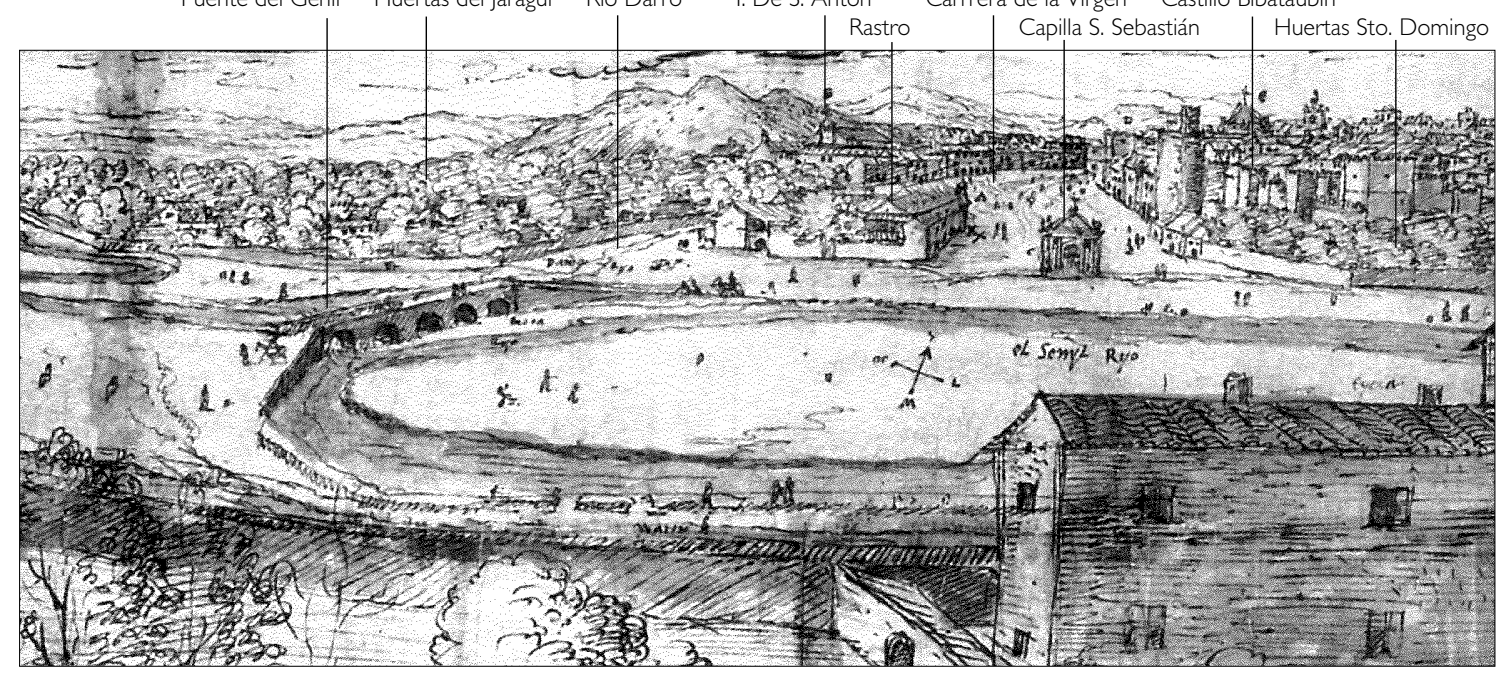

Fig. I. Anton V. der Wingaerde. Vista de Granada desde el Sur ( 1576). Dibujo preparatorio.

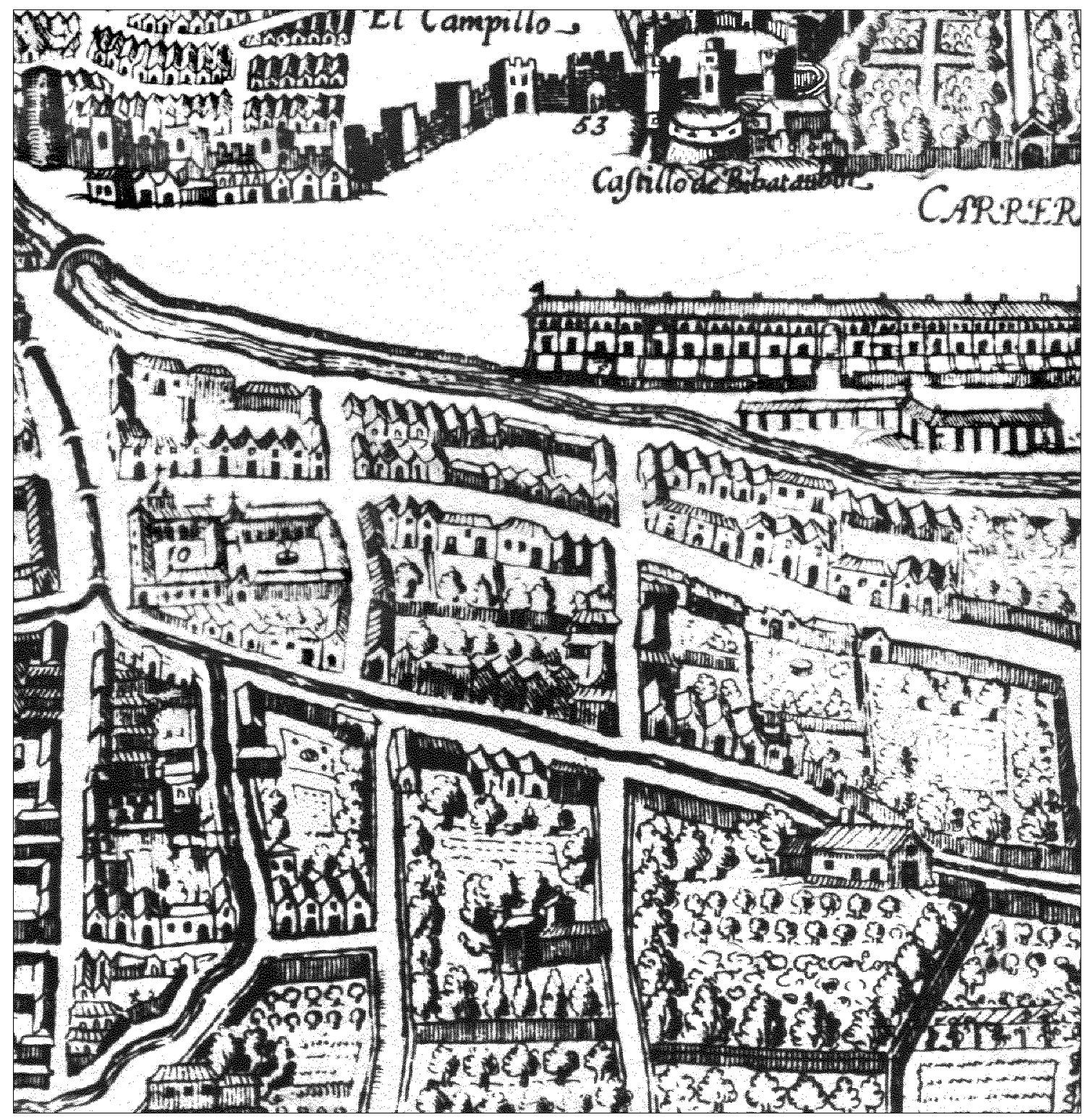

Fig. 2. A. de Vico. Plataforma de Granada. Detalle (Finales siglo XVI). 


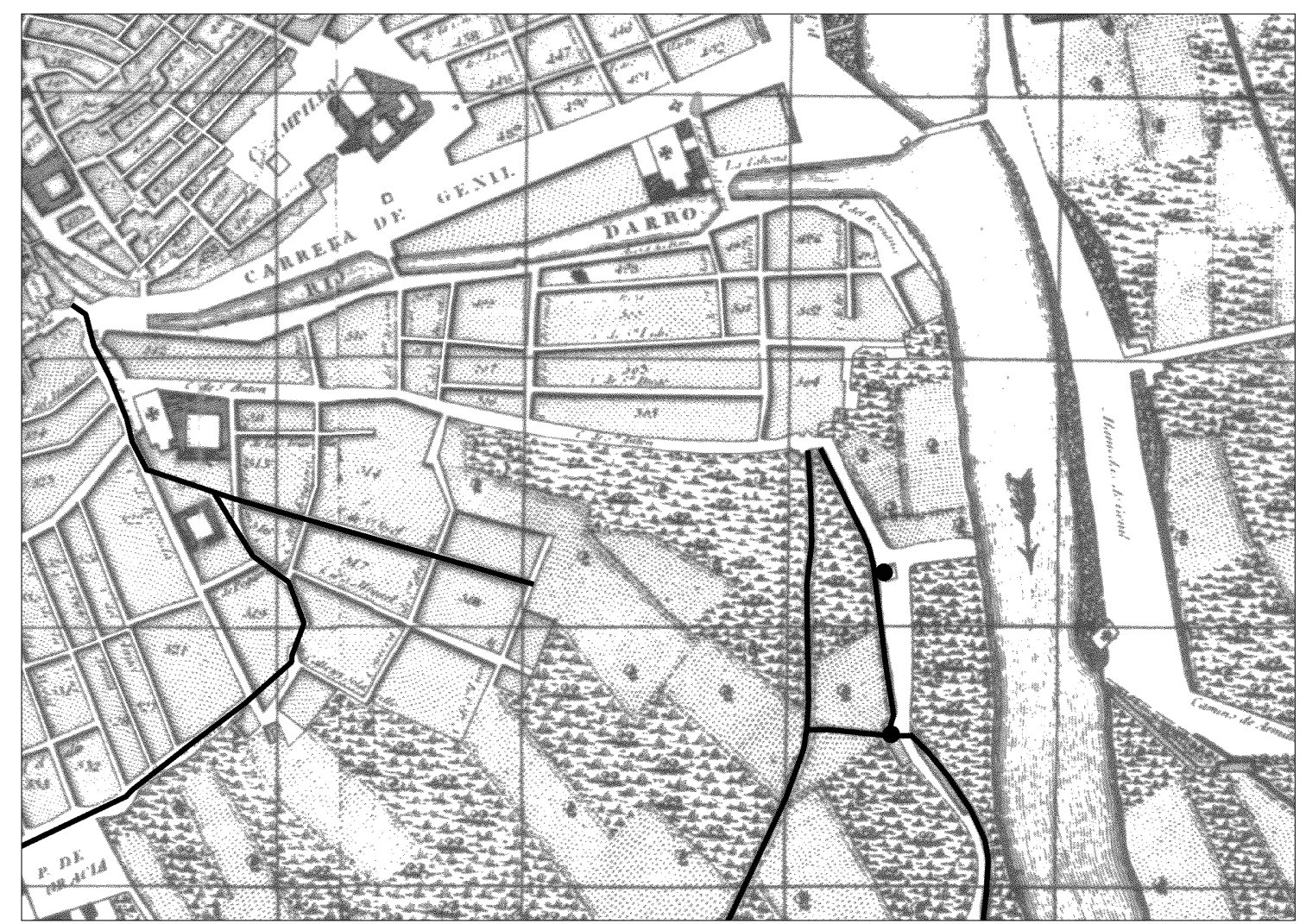

Fig. 3. F. Dalmau. Mapa Topográfico ( I 796). Se han marcado las conducciones indicadas por A. de Vico.

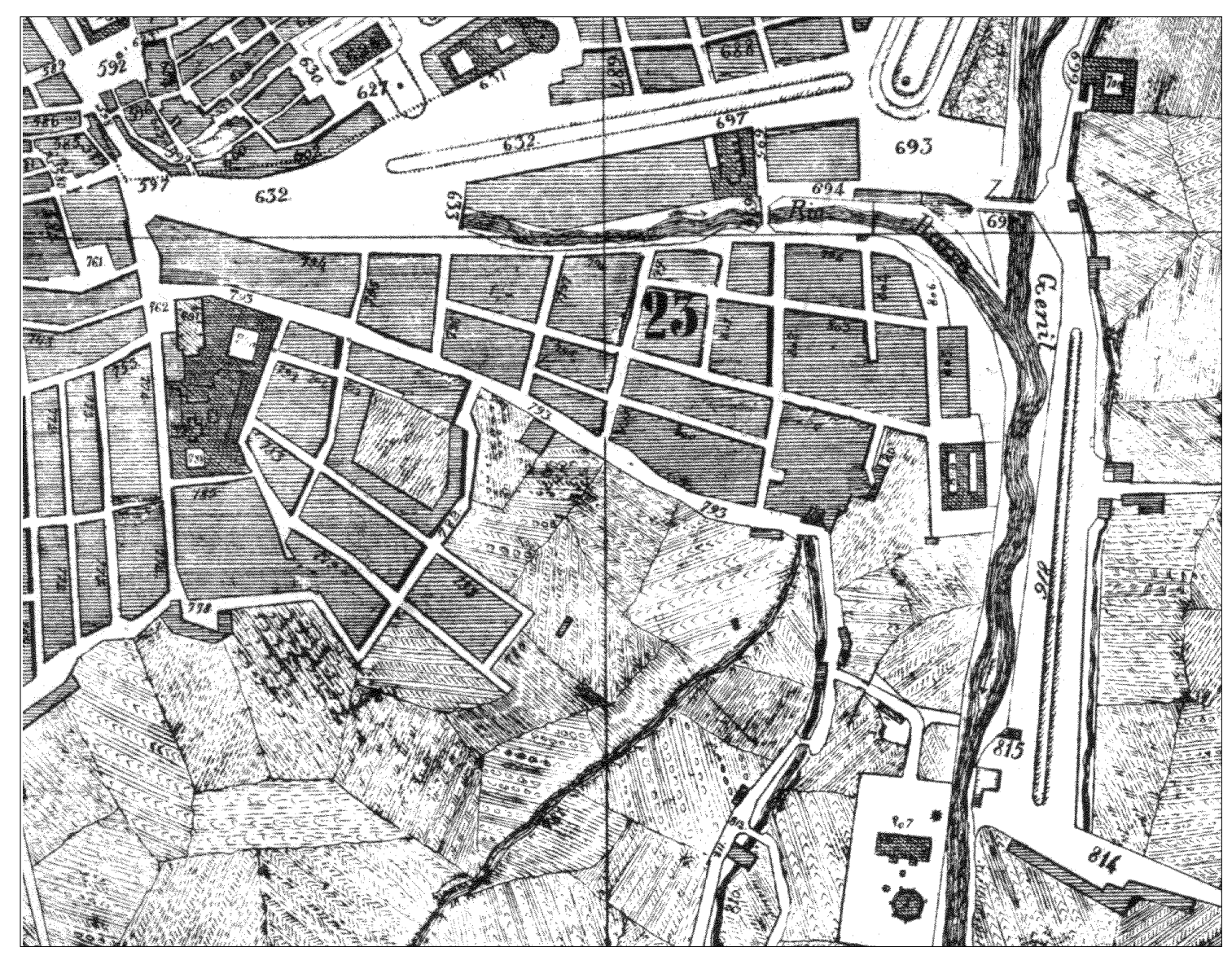

Fig. 4. R. Contreras. Plano de Granada (1 872). Detalle. 


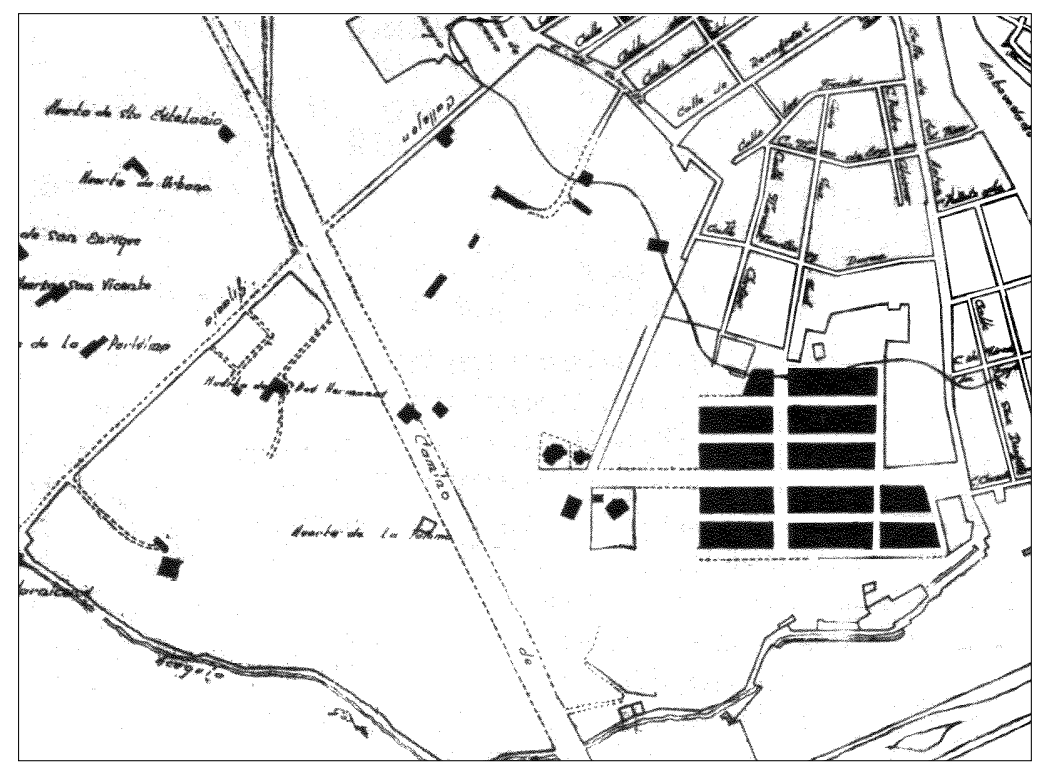

Fig. 5. Plano de

Granada (1935).

Fig. 6. Distribución de las edificaciones en el entorno rural de Granada (1982).
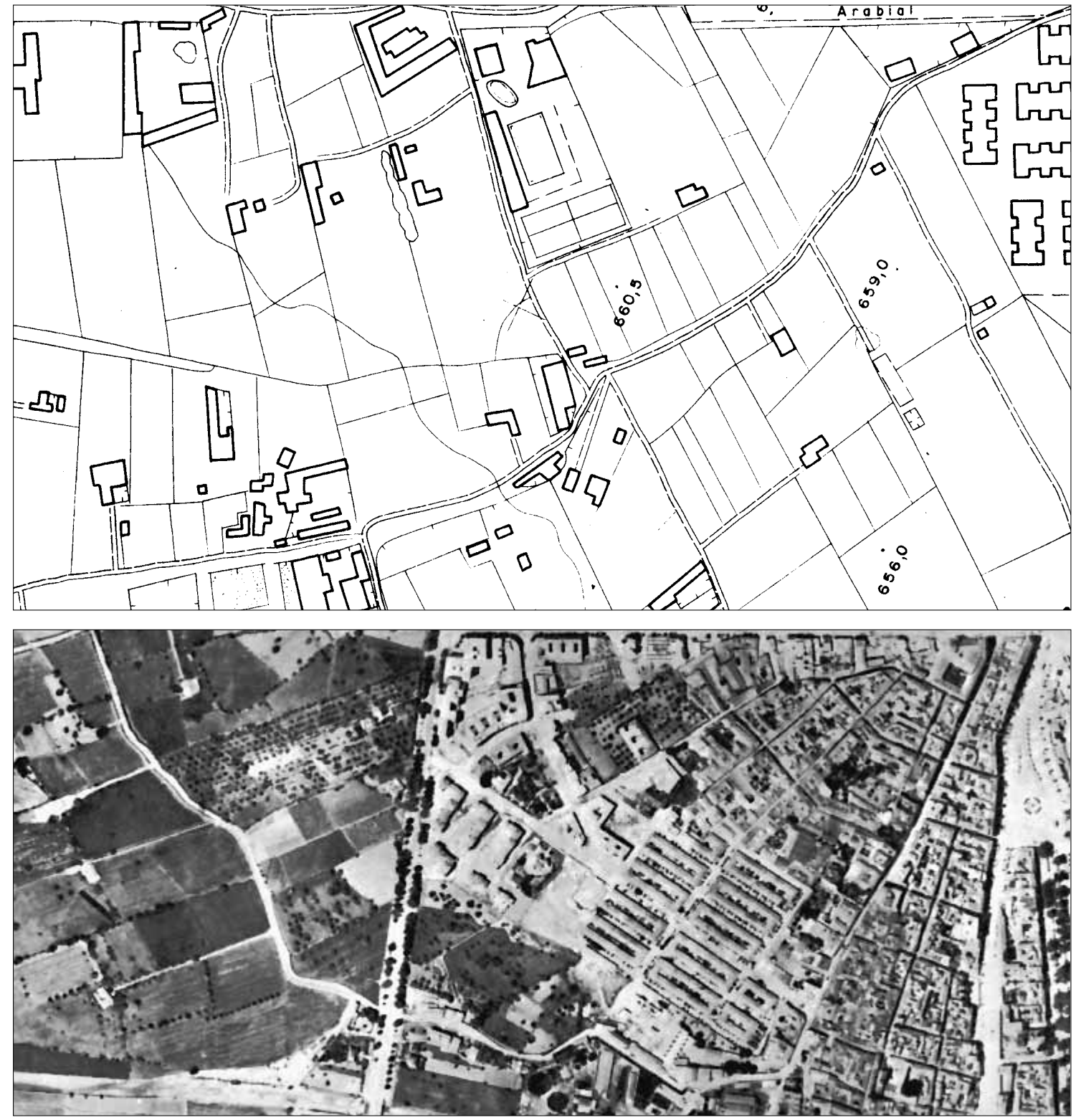

Fig. 7. Restos del parcelario agrícola en el entorno del barrio de S. Antón. Foto aérea de 1958. 
Fig. 8. Proceso de configuración urbana en función de las evidencias espaciales reconocibles.

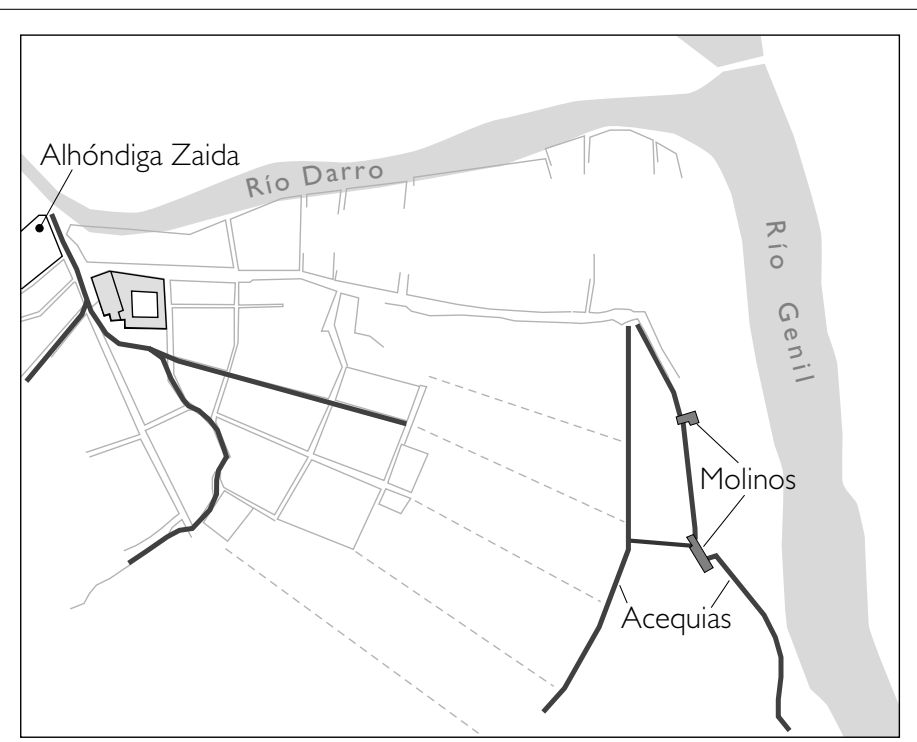

Elementos espaciales y funcionales hacia el final del dominio islámico

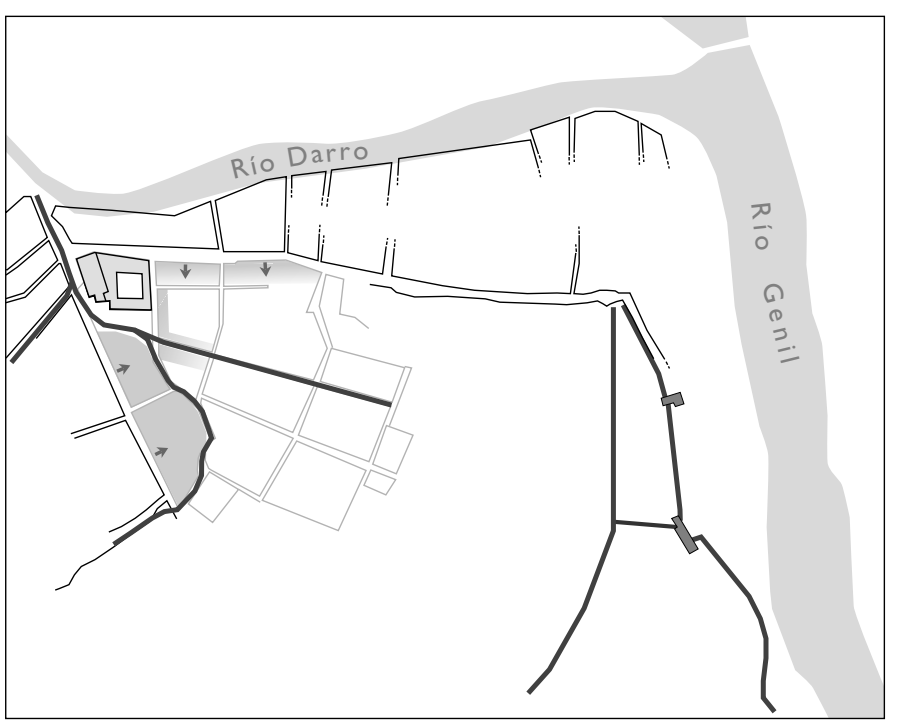

La urbanización periferica del siglo XVI

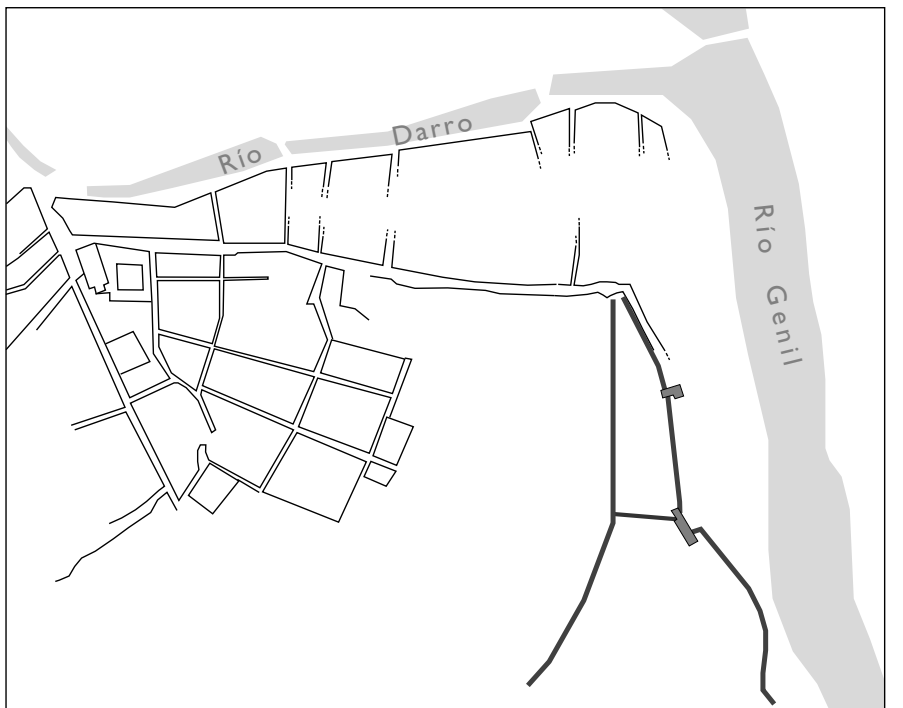

Estado de la trama urbana a finales del siglo XVIII según Dalmau 
Fig. 9. Trama urbana del barrio de S. Antón.

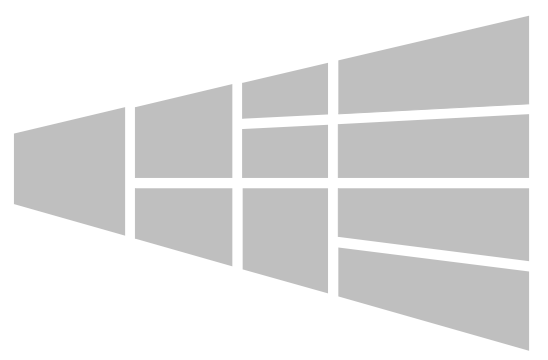

Organización tipo de un triángulo en función del parcelario del siglo XVIII

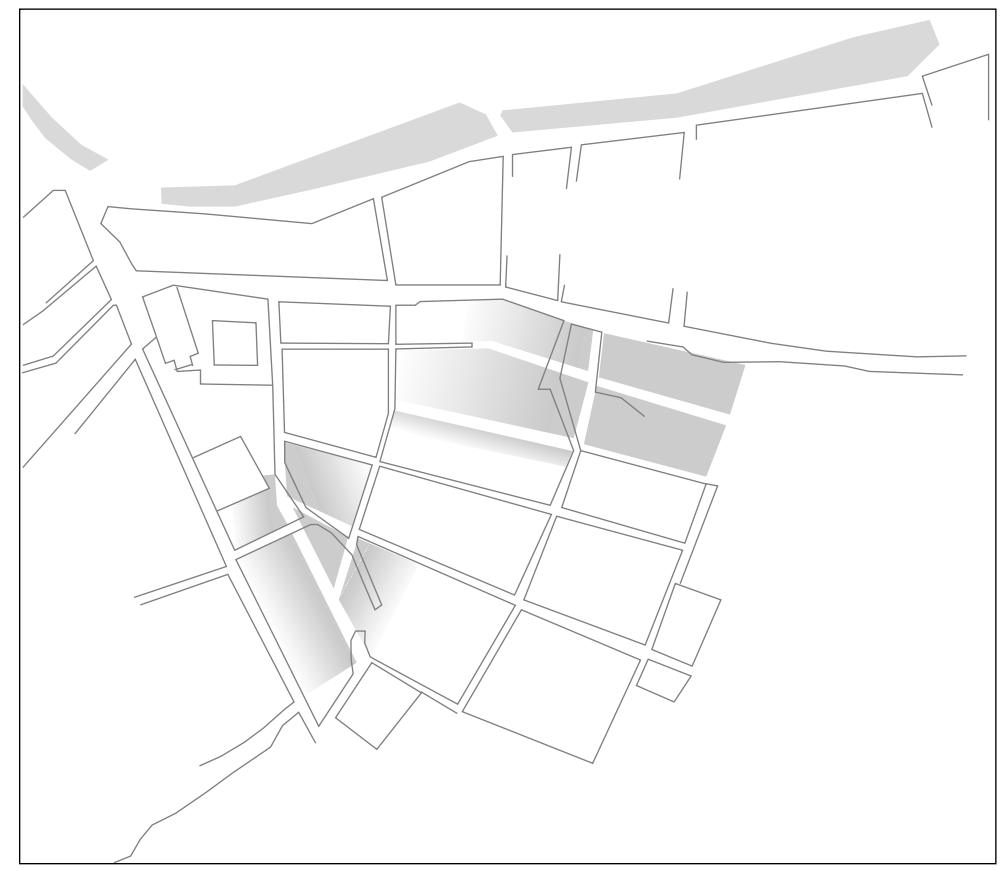

Estructura teórica en función de una trama tipo

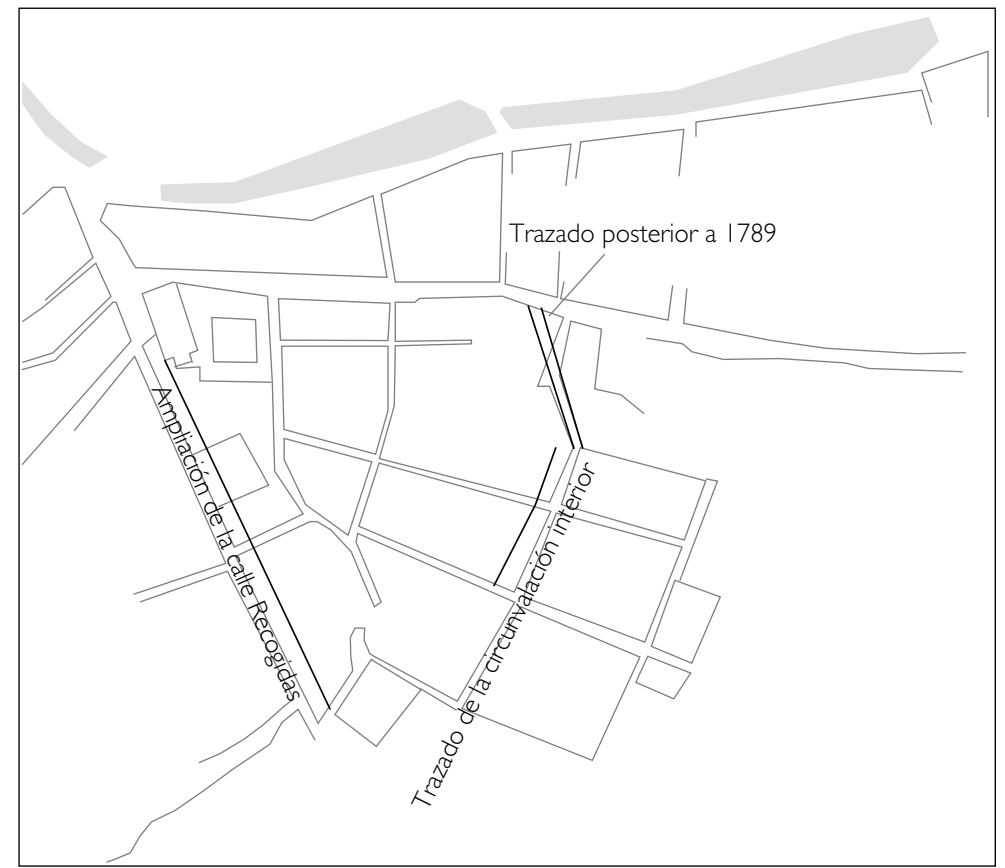

Principales modificaciones en el siglo XX 


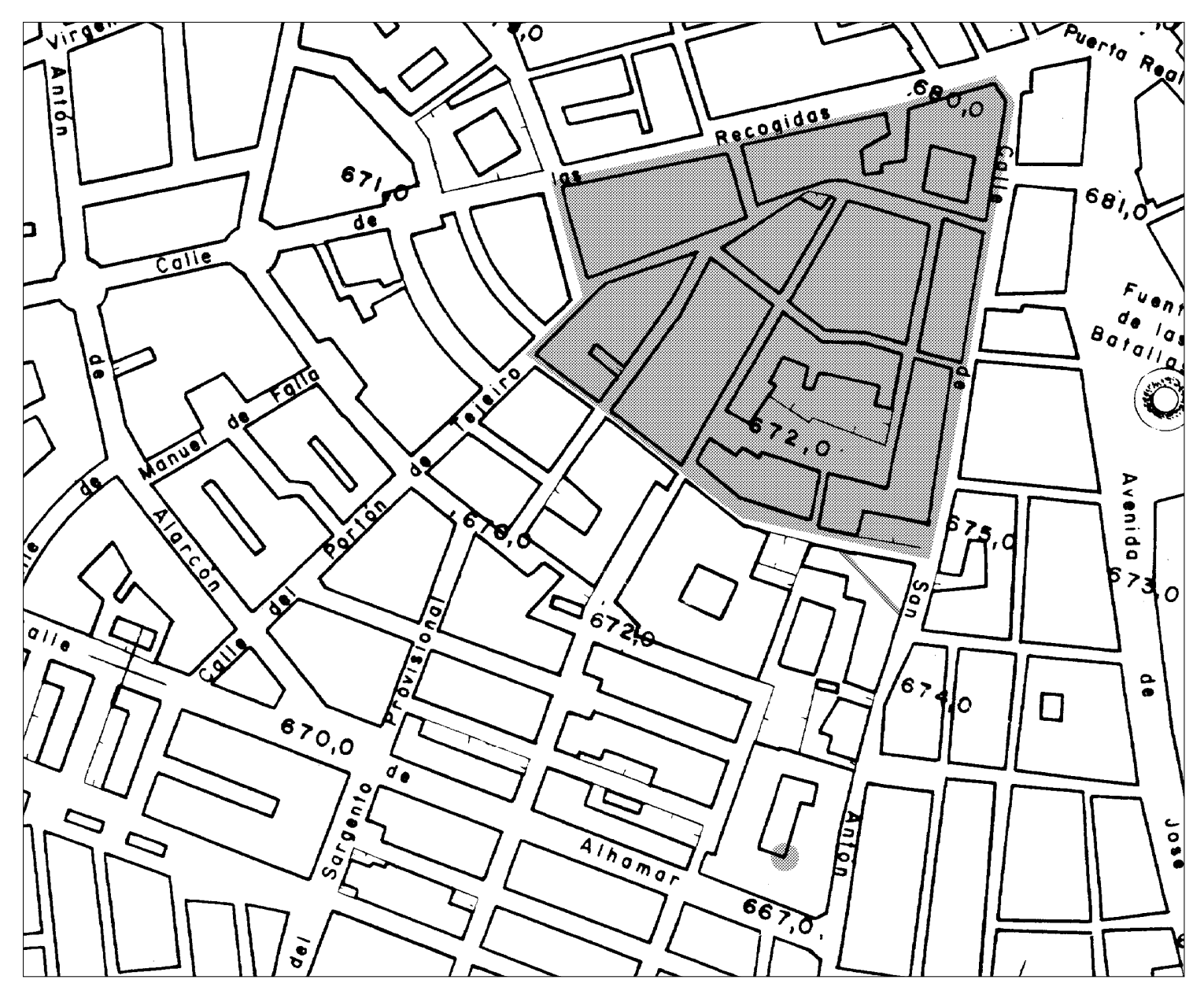

Fig. 10. Ubicación de los restos arqueológicos documentados respecto al área del Plan Especial.

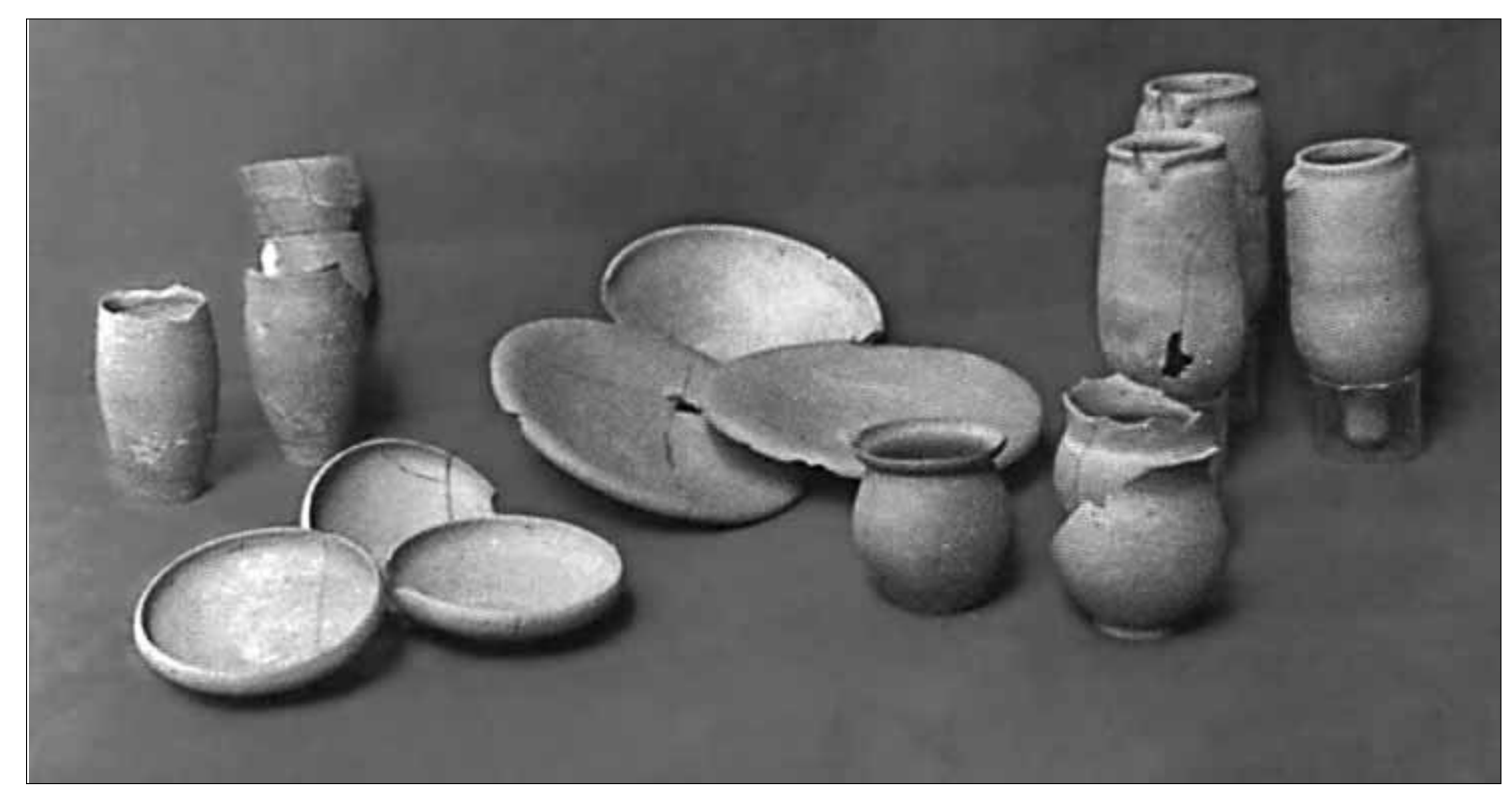

Fig. I I. Hallazgos arqueológicos en la zona. 


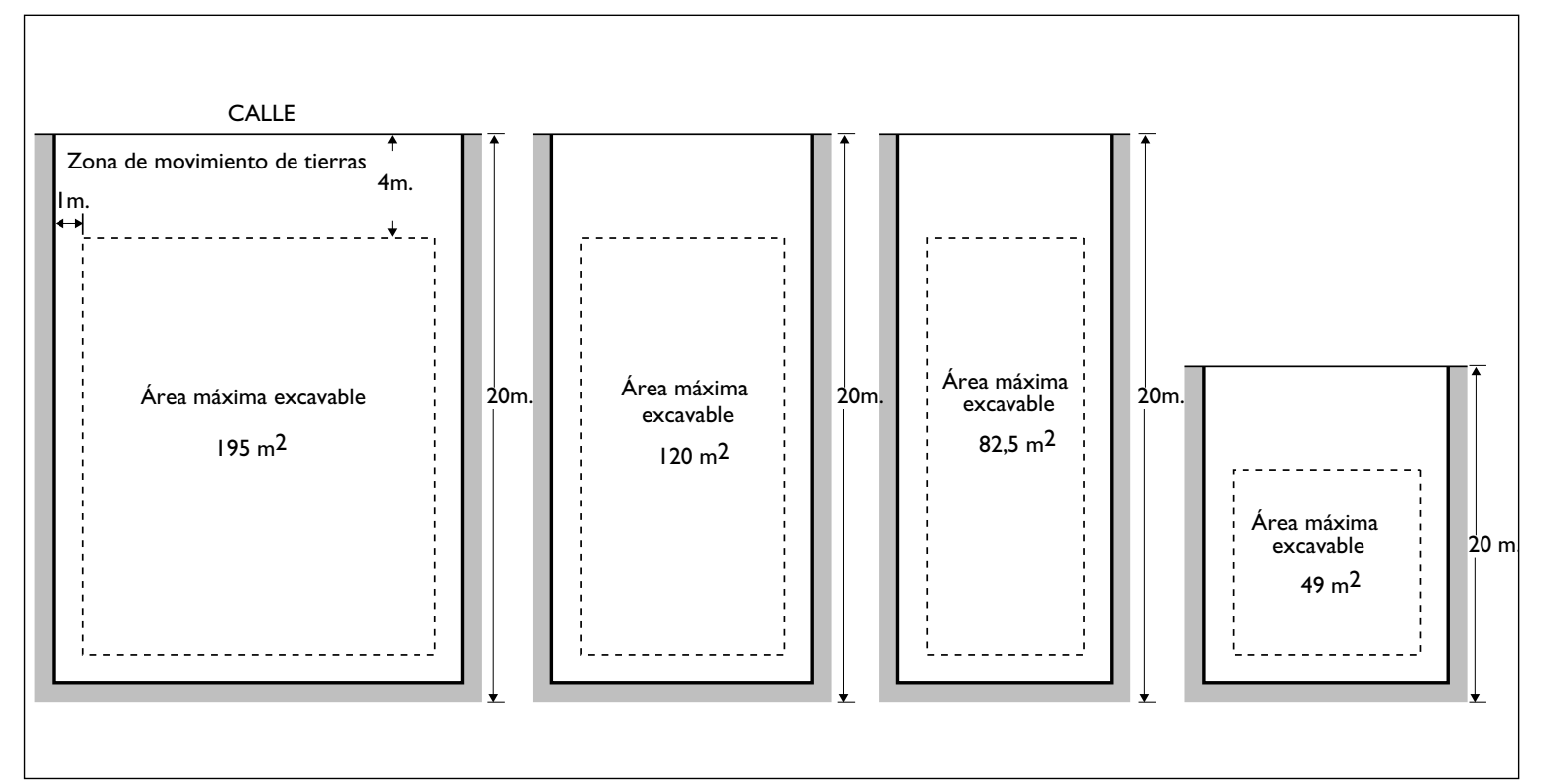

Fig. 12. Cálculo del área máxima excavable tipo en relación con la superficie del solar. 